OPEN ACCESS

Edited by:

Brian J. Bennett,

United States Department of

Agriculture, United States

Reviewed by:

M. Nazmul Huda,

University of California, Davis,

United States

Ulla Uusitalo,

University of South Florida,

United States

*Correspondence:

Annalisa Terranegra

aterranegra@sidra.org

Specialty section:

This article was submitted to

Nutrigenomics,

a section of the journal

Frontiers in Nutrition

Received: 30 September 2020 Accepted: 30 November 2020 Published: 23 December 2020

Citation:

Verduci E, Mameli C, Amatruda M,

Petitti A, Vizzuso S, El Assadi F

Zuccotti G, Alabduljabbar S and

Terranegra A (2020) Early Nutrition and

Risk of Type 1 Diabetes: The Role of Gut Microbiota. Front. Nutr. 7:612377.

doi: 10.3389/fnut.2020.612377

\section{Early Nutrition and Risk of Type 1 Diabetes: The Role of Gut Microbiota}

\author{
Elvira Verduci ${ }^{1,2}$, Chiara Mameli ${ }^{1}$, Matilde Amatruda ${ }^{2}$, Agnese Petitti ${ }^{1}$, Sara Vizzuso ${ }^{2}$, \\ Farah El Assadi ${ }^{3}$, Gianvincenzo Zuccotti ${ }^{1}$, Shaikha Alabduljabbar ${ }^{4}$ and \\ Annalisa Terranegra ${ }^{4 *}$
}

${ }^{1}$ Department of Pediatrics, Vittore Buzzi Children's Hospital, University of Milan, Milan, Italy, ${ }^{2}$ Department of Health Sciences, University of Milan, Milan, Italy, ${ }^{3}$ College of Health and Life Sciences, Hamad Bin Khalifa University, Doha, Qatar, ${ }^{4}$ Research Department, Sidra Medicine, Doha, Qatar

Type 1 diabetes (T1D) appears most frequently in childhood, with an alarming increasing incidence in the last decades. Although the genetic predisposition is a major risk factor, it cannot solely explain the complex etiology of T1D which is still not fully understood. In this paper, we reviewed the most recent findings on the role of early nutrition and the involvement of the gut microbiota in the etiopathogenesis of T1D. The main conclusions that are withdrawn from the current literature regarding alleviating the risk of developing T1D through nutrition are the encouragement of long-term breast-feeding for at least the first 6 months of life and the avoidance of early complementary foods and gluten introduction (before 4 months of age) as well as cow milk introduction before 12 months of life. These detrimental feeding habits create a gut microbiota dysbiotic state that can contribute to the onset of T1D in infancy. Finally, we discussed the possibility to introduce probiotics, prebiotics and post-biotics in the prevention of T1D.

Keywords: T1D, early nutrition, gut microbiota, probiotics, prebiotics, post-biotics

\section{INTRODUCTION}

Diabetes is a serious issue tackled globally. It's considered one of the top 10 causes of death in adults. According to the International Diabetes Federation Atlas, in 2019, the number of people with diabetes was $\sim 463$ million (1). Children represent $5-15 \%$ of total diabetic patients (2). Type 1 diabetes (T1D) is an autoimmune disease resulting from the destruction of insulin-producing $\beta$-cells in the pancreas which is promoted by T-cells (3), producing autoantibodies. Although the disease can occur at any age, T1D develops mostly in youth as $85 \%$ of all cases worldwide are diagnosed in individuals under 20 years of age (4). Results from EURODIAB study held in 22 European countries showed that T1D incidence rate in children under 14 years old increased by 3.4\% annually from 1989 to 2013 (5). A similar trend is reported by the Centers for Disease Control and Development (CDC) in the United States describing increasing incidence of T1D by $1.9 \%$ per year between 2002 and 2015 in children younger than 20 years old (6).

The etiology of T1D is complex and not fully understood; the genetic susceptibility along with environmental triggers can contribute to the development of the disease (7). Genetics play a crucial role in acquiring T1D as supported by familial inheritance studies; however, the inheritance pattern is complex and unclear (8). The risk of developing T1D is enhanced in individuals with multiple first-degree relatives affected by the disease (9). Besides, T1D is more common in males than in females (10), and children of fathers with T1D are more likely to get the disease than those who have mothers with T1D (11). However, among all children with genetic risk to develop diabetes, 
only a $5 \%$ of them develop the disease (12). The potential role of environmental factors is suggested by many facts: the increasing incidence of T1D in industrialized countries and in young children $(13,14)$; the low concordance among homozygotic twins (15); and the evidence that moving from a low incidence to a high incidence region increases the risk of the disease (16). Environmental factors that could trigger T1D progression in children are numerous: viral infections $(8,17,18)$, obesity $(19,20)$, lack of exercise, puberty, rapid longitudinal growth, psychological stress (19), diet and particularly high glycemic index diets (21), vitamin D deficiency and low diversity of gut microbiome $(8,19)$.

Currently, there is no clear evidence of the impact of nutritional and environmental factors in the development of autoimmunity and T1D. Understanding their pathogenetic role could be a crucial strategy for the prevention of the disease in early infancy. In this review we will discuss the most recent findings on the role of early nutrition and the involvement of the gut microbiota in the etiopathogenesis of T1D.

\section{EARLY NUTRITION AND ITS ROLE IN T1D}

Recent studies show that $\beta$-cells autoimmunity develops in the first years of life; indeed, in most cases autoantibodies can be detected by 2 years of age (14). This led researchers to look for environmental factors that act early in life, and special attention has been directed toward nutritional factors (22).

Many retrospective and prospective studies have been conducted to define the role of dietary factors in the development of T1D; however, results are still controversial. The inconsistency of these results might also reflect the influence of genetic background on the individual susceptibility to external factors. Moreover, most of these studies focused on adult diet, whereas recent researches highlighted the role of infant feeding practices and early nutrition in the development of T1D (23). Hereafter, we will review and discuss the available evidence about the role of breastfeeding and the introduction of complementary and single foods, such as cow milk and gluten, in the onset of T1D.

\section{Breastfeeding}

Breastfeeding has several beneficial effects on maternal and child health (24), and many studies were performed to assess its potential impact on T1D ending in controversial results. Data from two large population-based cohorts of a total of 155,392 Danish and Norwegian children revealed that the risk of T1D doubled in those who were not breastfed. No significant difference was observed upon comparing the duration of breastfeeding (25). However, data from a meta-analysis of 43 studies, including 9,874 patients with T1D, showed that exclusive breastfeeding for $>2$ weeks is associated with a reduction in the risk of diabetes by $15 \%$ while a prolonged duration ( $>3$ months) resulted in a weaker association. No association was found for non-exclusive breast-feeding independently from the duration (26). Similarly, conflicting results were obtained from previous prospective cohort studies assessing the link between breastfeeding and beta cells autoimmunity in children with genetic susceptibility to T1D (27).
There are many hypothetical mechanisms implicated in the protective effect of human milk. Breastfeeding has a central role in influencing gut microbiota and immunity. It contains nutrients and bioactive substances (cytokines, growth factors, immunomodulators, oligosaccharides) that promote the maturation of immune system and modulate its functions $(16,28,29)$. A study conducted on diabetes-prone rats showed that breastfeeding decreases the number of activated lymphocytes and the production of pro-inflammatory cytokines (IL-4, IL-10, IFN- $\gamma$ ) while it increases the number of $\mathrm{T}$ regulatory cells $(\mathrm{CD} 4+\mathrm{CD} 25+$ FoxP3+). In particular, long-term exclusively breastfed rats have reduced number of $\mathrm{CD} 4+\mathrm{T}$ cells in the mesenteric lymph nodes and an expansion of both effector and natural $\mathrm{T}$ regs. Exclusive and prolonged breastfeeding reduced the risk of autoimmunity by limiting the introduction of external antigens and by shifting the balance between tolerogenic cells and autoreactive cells $(30,31)$. A recent research on non-obese diabetic mice (NOD-mice) showed that a 4-weeks supplementation with human milk oligosaccharides (HMOS) leads to a significant reduction in T1D incidence (29). Furthermore, human milk bacteriome (HBM) could play a role in immunoregulation through competitive exclusion of pathogenic bacteria and active production of antimicrobial and metabolic molecules (32). In-vitro studies demonstrated that HBM-derived Lactobacilli have anti-bacterial activity against Staphylococcus aureus in vitro, and it also inhibits adhesion of Salmonella enterica in infected mice (33). HBM inhibits anaerobic and facultative bacteria by producing acids and therefore lowering gut $\mathrm{pH}$ (34). HBM-derived Lactobacilli strains have immunomodulatory activity in vitro by modulating immune cell function, cytokines and chemokines. This effect was not observed with probiotic bacteria not derived from human milk (35). In addition, breast milk contains insulin that has a protective effect against autoimmunity as was proved in rats by driving the maturation of gut epithelium as well as in humans by downregulating production of IgG antibodies to bovine insulin (16). A case-control analysis of fatty acids serum concentration in infants with genetic susceptibility to T1D, within the Finnish Dietary Intervention Trial for the Prevention of Type 1 Diabetes (FINDIA), at the age of 3 and 6 months revealed that docosahexaenoic acid (DHA) levels were inversely associated to islet autoimmunity, while higher $n-6: n-3$ fatty acids ratio increased the risk. Moreover, the quantity of breast milk consumed per day was inversely associated with primary insulin autoimmunity, while the quantity of cow milk consumed per day was directly associated. Even if further studies are warranted to clarify the independent role of fatty acids in the development of T1D, omega-3 long chain polyunsaturated fatty acids consumed during breastfeeding might provide protection against type 1 diabetes-associated autoimmunity (36).

\section{Complementary Foods}

According to World Health Organization (WHO) recommendations for infant feeding, exclusive breast-feeding represents the ideal nutritional strategy during the first 6 months of life for its beneficial effects on maternal and infant health (37). After 6 months of age, human milk alone is not sufficient to 
meet the energetic and nutritional needs of the baby. From this age on, the introduction of complementary foods is required to ensure the adequate infant growth and development. Any food can be offered by gradually increasing consistency and variety; however, sugars, salt and sugar-sweetened beverages should be avoided (38).

Evidence from systematic reviews revealed that complementary feeding initiation before 3-4 months of age is associated with higher risk of allergic conditions, while gluten introduction before 4 months can be linked to the development of celiac disease and type 1 diabetes mellitus (39). The Type 1 Diabetes Prediction and Prevention Project (DIPP), a prospective cohort study, aimed to evaluate the effect of complementary foods introduction on $\beta$ cell autoimmunity. More than 3,000 newborn babies with genetic susceptibility to T1D were periodically screened for $\beta$ cell autoimmunity seroconversion until 12 months of age. The study revealed that early introduction (between 3 and 4 months) of fruit, berries and roots was associated with a higher risk to develop $\beta$ cells autoimmunity (27). Nevertheless, there is no consisting evidence that delaying the introduction of certain foods has a beneficial role in preventing T1D. Results are often discordant or inconclusive, and more data from large randomized controlled trials are needed.

\section{Cow Milk}

According to current recommendations for infant feeding, cow milk introduction should be avoided before 12 months of life: early exposure has been linked to higher risk of developing allergy and to occult gastrointestinal blood (38). In the past years, different authors studied cow milk as potential trigger for T1D with discordant results, finding both an increased (40) or a decreased risk (41) of developing beta cells autoimmunity and T1D. Conversely, the TRIGR study on genetically susceptible children, found no protective effect of extensively hydrolyzed casein-based formula compared to a standard formula in the development of islet autoimmunity (42). To similar conclusions ended the prospective cohort study The Environmental Determinants of Diabetes in the Young (TEDDY study) which collected information on feeding pattern of 8,506 children with increased genetic risk for type 1 diabetes and founded no significant association with islet autoimmunity in infants fed with extensively hydrolysed compared to nonhydrolysed formula feeding (43). Cow milk proteins are known to have an intrinsic allergenicity particularly beta-lactoglobulin, bovine serum albumin, $\alpha$-casein, $\kappa$-casein (44). Oral tolerance to cow milk antigens could be impaired in individuals with a genetic susceptibility to T1D, and this could trigger autoimmunity $(45,46)$. Bovine albumin and insulin have also been considered as possible triggers for autoimmunity given their similarity to endogenous pancreatic antigens $(21,30,47)$. Immunological cross-reactivity between bovine proteins and beta cells' antigens could represent another hypothetical mechanism explaining the association between cow milk and T1D (48). Early exposure to cow's milk has been associated with increased gut permeability and altered barrier function, which predispose to exogenous antigen reactivity and immunologic dysregulation (49). Recent observations suggest that altered intestinal permeability could be a key step in the pathogenesis of the subclinical enteropathy underlying type 1 diabetes (50). It's worth to note the different position of fermented milk and dairy products known for the beneficial effect on human health (51). A recent systematic review on the effect of yogurt and fermented milk in infants and toddlers (0-24 months) confirmed the health benefits also in this age class, reporting positive effects on acute diarrhea as well as atopic dermatitis and food sensitivity. The same review reported the benefic effect on the gut microbiota that we discussed more in detail in Section Complementary Feeding-Induced Microbial Changes and Immune Response (52). No direct data have been found of the effect of the yogurt and fermented milk in T1D children.

\section{Gluten and Cereals}

In the last decade, studies on rodents revealed a potential diabetogenic effect of gluten by inducing an immune dysregulation (53). According to the study of Funda et al., a gluten-free diet in NOD mice prevented the progression of T1D (54). Gluten proteins resist to enzymatic digestion and represent a constant immunologic trigger that can lead to immune dysregulation. This mechanism could explain gluten role in the similar pathogenic pathways of celiac disease and T1D (55). The Diabetes Autoimmunity Study in the Young (DAISY) examined dietary pattern of 1,835 infants at increased risk for diabetes (development of at least two specific autoantibodies in succession): islet autoimmunity and diabetes progression were not influenced by gluten cumulative amount in the first years of life, while introduction of gluten before 4 months was significantly associated with a higher risk of developing T1D (56). Nevertheless, previous prospective observational cohort studies could not find any link between the time of gluten introduction and islet autoimmunity (55). Accordingly, a small randomized controlled trial found no significant beneficial effect from delaying gluten introduction from 6 to 12 months (57).

The most recent opinion of experts regarding the appropriate age for introducing complementary foods concluded that gluten introduction before or after 6 months of age has neither beneficial nor negative effect on the risk of developing T1D. Gluten can be introduced between 4 and 12 months, but earlier introduction (before 4 months) is associated with the development of celiac disease in children at higher risk $(56,58)$. The prospective birth cohort FINDIA followed 6,081 infants with genetic susceptibility to type 1 diabetes up to 6 years and revealed that higher intake of oats, gluten-containing cereals and gluten (estimated trough 3 days food record) is associated with an increased risk of islet cell autoimmunity (59). The exposure to gluten was analyzed in a cohort od 6,605 children from the TEDDY study and the data showed that higher gluten intake during the first 5 years if life was associated with an increased risk for celiac disease (60). Further studies are needed to clarify the pathogenetic role of gluten and whether a gluten-free diet could be an essential component of medical nutrition therapy to prevent the onset and progression of T1D. 


\section{Micronutrients}

Increasing attention has been recently focused on the potential role of micronutrients intake during early life in etiology of T1D. As clearly outlined in a recent review, vitamin $\mathrm{D}$ and $\mathrm{E}$ and zinc are the most studied factors (22).

Vitamin $\mathrm{D}$ is commonly known for regulating of calcium and phosphate metabolism but also exerts several immunomodulatory effects on innate and adaptive immune system. Association between low levels of serum 25hydroxyvitamin $\mathrm{D}$ have been linked to increased risk of many immune-related disorders, including T1D (61). Recently, Norris et al. described that higher serum levels of $25(\mathrm{OH})$ vitamin $\mathrm{D}$ are associated with lower risk of islet autoimmunity in children at increased genetic risk for T1D (62). However, the results of follow-up studies on children showed no significant association between vitamin $\mathrm{D}$ status at a pre-diagnostic stage and T1D progression later in life (63-65). Inconsistent results came from studies on maternal vitamin $\mathrm{D}$ supplementation for prevention of T1D in offspring (66). Moreover, a recent systematic review of randomized controlled trials suggests that vitamin $\mathrm{D}$ supplementation in both children and adults plays a role in the control of disease activity by reducing insulin requirement and stimulating C-peptide levels (67) but there is still no evidence of long-term effects of vitamin D early supplementation on T1D risk.

The action of vitamin A to control immune response has led to a growing hypothesis of potential role of vitamin A in T1D as an autoimmune disease. Vitamin A regulates the adaptive and innate immune responses by different mechanisms for example, by its ability to transform Th1 to Th2 lymphocytes. A recent review reported that both vitamin A and all-trans retinoic acid effectively induced immune tolerance that inhibited islet inflammation and progression to diabetes (68). Further studies are needed to evaluate the vitamin A modulating effect on the development of T1D.

Recent research has been focused on the potential role of oxidative stress induced by free radicals in the pathogenesis of T1D. Based on this assumption, micronutrients with antioxidant properties as vitamin $\mathrm{C}$ (ascorbic acid), zinc ( $\mathrm{Zn}$ ) and selenium (Se) may play a role in the pathogenesis and exacerbation of this disease. Mattila et al. examined plasma ascorbic acid concentration in children at high genetic risk of T1D (within the TEDDY study), initially at 6 and 12 months and then annually up to 6 years of age. The Authors found that higher plasma ascorbic acid levels were associated with decreased islet autoimmunity risk, but not with T1D risk progression (69).

Results from animal studies revealed that seleniumdependent proteins (seleno-proteins) with redox properties are involved in glucose metabolism, given that insulin release and signaling are influenced by the cellular redox potential (70). Significantly lower levels of $\mathrm{Se}$ and $\mathrm{Zn}$ were found in children affected by T1D and glycosylated hemoglobin (HbA1c) levels appeared inversely correlated with Se and $\mathrm{Zn}$ levels (71). Moreover, $\mathrm{Zn}$ concentration in drinking and stream water has been inversely associated to T1D $(72,73)$.

\section{THE POTENTIAL ROLE OF THE GUT MICROBIOTA AS AN ENVIRONMENTAL TRIGGER FOR T1D}

Consistent evidence from literature shows that the gut microbiota can influence the innate and adaptive immune system $(74,75)$, and many studies have highlighted the longterm impact of shaping the microbiota during early life on the immunity (76-80). The term "Microbiota" was first used in 2001 by Lederberg and McCray (81) and has been described as the "assemblage of microorganisms present in a defined environment" (82). The human body hosts up to 100 trillion symbiotic bacteria, primarily in the intestinal track, defined as the gut microbiota (83).

As for many other autoimmune diseases, the gut microbiota has been implicated in T1D pathogenesis through multiple mechanisms that involve the intestinal inflammation $(49,84)$, the epithelial barrier integrity $(85,86)$ and the modulation of tolerance to dietary antigens (87). The role of the gut microbiota in T1D pathogenesis was first discovered in animal

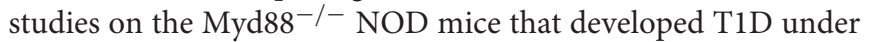
germ-free conditions in contrast to pathogen-free conditions (88). Antibiotic treatment exhibited a prompting response for T1D development in the non-obese diabetic (NOD) mice by selectively eliminating specific bacterial species $(89,90)$. Interestingly, the antibiotic treatment had a more pronounced influence at the early age (from birth to day 28) compared to the mice that were given antibiotics starting 8 weeks of age until the disease's onset (91). Similarly, probiotics can alter the microbial profile by enhancing favorable bacterial species. In NOD mice (92-94) and bio-breeding diabetes-prone (BB-DP) rats (95), probiotics administration prevented T1D development. Dysbiosis, is hypothesized to be the underlying factor behind the triggered autoimmune response. A recent cohort study confirmed a microbial dysbiosis state in children who had multiple islet autoantibodies as well as children who were recently diagnosed with T1D; the reported dysbiosis was linked to permeability in the epithelial membrane (96). The microbiome in the duodenal mucosa showed a disease-specific manner in T1D patients, and it was associated with the expression of T1D-related genes (97). Consistently, taxonomic and functional differences in the gut microbiota were observed in T1D cases compared to healthy controls and to non-autoimmune diabetes cases such as Maturity Onset of Diabetes of the Young (MODY) (98).

Human studies conducted on diabetic patients have demonstrated the presence of dysbiosis that is associated with increased intestinal permeability and mucosal inflammation contributing to the development of islet autoimmunity $(28,99)$. In children with $\mathrm{T} 1 \mathrm{D}$, the microbiota is characterized by a low bacterial diversity, reduced microbiota stability, an increased amount of Bacteroides, Clostridium and Veillonella and a reduced number of Firmicutes $(100,101)$. Interestingly, Bacteroides dorei was found enriched in T1D-prone children before they developed autoimmunity (102). Moreover, at the onset of autoimmunity of $\beta$-cells, the species Bacteroides ovatus was found 16 times more abundant in T1D cases than in the 
control group; several other Bacteroides species were enriched as well (103). In T1D patients a decreased abundance of Prevotella, Bifidobacteria, and Lactobacillus was reported; this led to reduced production of butyrate and lactate that have anti-inflammatory and immunomodulator functions and can improve the integrity of the mucosal barrier (104). The TEDDY study concluded that the microbiome in healthy controls resulted in a higher expression of genes related to fermentation and biosynthesis of short-chain fatty acids, that have a protective role against the development of autoimmunity. The healthy subjects had higher levels of Lactobacillus rhamnosus in their stool samples (105).

The mechanism of how the immune response is translocated from the intestine to the pancreas is still elusive. However, it is known that the mesenteric lymph nodes, which are part of the gut-associated lymphatic tissues (GALT), are linked to the pancreatic lymph nodes (106). Moreover, evidence shows that the intestinal immune response can be resembled in the pancreas by allowing $\mathrm{T}$ cells imprinted with homing receptors, that have adhesion molecules expressed in the pancreas, to infiltrate the pancreas and attack the islets cells (107).

\section{EARLY NUTRITION AS MODULATOR OF MICROBIOTA IN RELATION TO T1D}

Results from animal and human studies confirm that diet is one of the primary modulators of the gut microbial community also in T1D (108). A high carbohydrate (CHO) diet has been associated with a higher abundance of Prevotella (109) which was found reduced in T1D subjects $(110,111)$. Diets rich in fat increase the abundance of Bacteroides genus $(109,112)$, that was found enriched in children prone to develop T1D (102) as well at the onset of $\beta$-cells autoimmunity in T1D cases (103).

The role of the gut microbiota significantly lies in the effect of the metabolites that they produce such as vitamins (113, $114)$, short-chain fatty acids (SCFA) (115-117), indole derivatives $(118,119)$ and organic acids (120). Consistently, high fiber diets yielding a high amount of butyrate and acetate, separately and combined, contributed to improved immune regulation and protection against T1D through different mechanisms. In diabetes-prone rats, although introducing butyrate during early life did not prevent T1D, it seemed to be associated with delayed T1D progression by reducing gut leaking compared to the control group (121). In humans, achieving a causal relationship among diet, SCFAs and T1D development is still challenging. Here below, we discuss the potential mechanism of early nutrition as modulator of microbiota in triggering T1D that remains not well elucidated.

\section{Breast-Feeding Effect on Microbiota of T1D Infants}

In the past, the newborn babies were thought to have a sterile gut at birth; however, recent evidence suggests that the fetus is exposed to colonization of intrauterine bacteria (122). Several studies confirmed presence of bacteria in meconium samples in the $65-75 \%$ of infants with full-term delivery $(123,124)$. The variability of newborn microbiota is influenced by many factors such as the mode of delivery, vaginal delivery or cesarean section (122), and breastfeeding. The similarity between mother's milk bacteria and infant gut flora confirmed that microbiota can be transferred through breastfeeding. The diversity and the composition of infants' microbiota seem to be influenced by the amount and the duration of breastfeeding (125). The microbiota of infants exclusively breastfed for 6 months is enriched with Bifidobacterium longum subsp. Infantis, which is involved in child's immunity $(126,127)$. It belongs to lactic acid bacteria, Bifidobacterium and Lactobacillus, which can break down human milk oligosaccharides (128).

Former studies reported that the bacterial colonization was significantly different between breastmilk-fed and formula-fed babies (129-131). For instance, Lactobacillus johnsonii/L.gasseri, L. paracasei/L. casei, and Bifidobacterium longum are prevalent in exclusively breastfed infants whereas Clostridium difficile, Granulicatella adiacens, Citrobacter spp., Enterobacter cloacae, Bilophila wadsworthia are the most common bacterial species in the 4-months formula fed infants (132). Moreover, E. coli was found to be significantly lower in the gut microbiota of breastfed infants compared to formula-fed infants (133). Interestingly, Davis et al. described changes in the gut microbial composition upon shifting from breastfeeding to cow milk after 1 year and a half of life: $C$. difficile almost disappeared with a relative increase in Bacteroides spp., Blautia spp., Parabacteroides spp., Coprococcus spp., Ruminococcus spp., and Oscillospira spp. and decrease of Bifidobacterium spp., Lactobacillus spp., Escherichia spp., and Clostridium spp. (134).

Breast feeding importance in modulating the gut microbiota in relation to T1D has been tackled in many studies with controversial results $(8,23)$. In breastfed infants, an abundance of Bifidobacterium was observed, which has been inversely correlated with T1D risk by a number of cross-sectional and longitudinal human studies $(126,128)$. Lactobacillus and Bifidobacterium species in breast milk have a protective role in preserving the gut integrity and stimulating the growth of Firmicutes bacteria phylum, that is found deficient in people with T1D (103, 135). The TEDDY study demonstrated a temporal development of the gut microbiome in T1D infants that can be divided in three phases: a developmental phase (months 314), a transitional phase (months 15-30), and a stable phase (months 31-46). Breastfeeding, either exclusive or partial, was associated with the microbiome temporal structure, with higher levels of Bifidobacterium species (B. breve and B. bifidum) at the development phase, and the cessation of breast milk resulted in faster maturation of the gut microbiome, marked by the phylum Firmicutes (136).

Furthermore, breast milk can be a source of insulin hormone, that enhances the gut microbiota diversity through the stimulation of the Gammaproteobacteria (137), which is crucial for infant gut microbiota maturation, especially during the first weeks of life (138). Leptin is another hormone contained in breast milk which is involved in beneficial bacterial metabolic pathways, such as stimulating microbial diversity and reducing bacterial proteases linked to intestinal permeability and inflammation (137). In addition, breast milk contains non-digestible oligosaccharides which promote the growth of 
beneficial bacteria, leading to a balanced microbiota (139). The beneficial effect of a breast milk rich in omega-3 fatty acids observed in the FINDIA study (36) can be explained with an involvement of the gut microbiota, as demonstrated in an animal model of type 2 diabetes. Animals fed with flaxseed oil, rich in omega-3, showed improved glycemic indexes, blood lipids, inflammatory cytokines and reduced levels of Firmicutes and Blautia, as well as an increase in the levels of Bacteroidetes and Alistipes. SCFA were also improved in the supplemented animals (140). No data are available on effect of omega-3 on gut microbiota of T1D patients.

Formula milk composition was also investigated in a multicenter double-blind clinical trial (from the FINDIA study), where 1,113 infants with HLA-conferred susceptibility to T1D were sorted into 3 groups and given respectively cow milk formula, hydrolyzed formula or bovine insulin-free formula during the first 6 months of life. The primary finding was that infant fed with insulin-free formula had a lower incidence of beta-cell autoimmunity by 3 years of age (141). In addition, an increase in Bacteroides and a decrease in Bifidobacterium amount were found in formula-fed infants who shifted to seroconversion (142).

\section{Complementary Feeding-Induced Microbial Changes and Immune Response}

It is demonstrated that the diet composition (i.e., amount of fat, sugars, calories, vegetarian diet, etc.) affects the microbiota composition and the intestinal function (104). More importantly, nutrition in early life plays a critical role in the development of microbiota and the mucosal immune system starting from the breastfeeding habits to the introduction of solid food.

Early introduction of cow milk has been associated with increased intestinal permeability and gut inflammation (14). Children with T1D express higher levels of circulating antibodies against cow milk proteins ( $\beta$-lactoglobulin, insulin, albumin); this could be the effect of a dysregulated immune response or an increased intestinal permeability (14). On another side, fermented milk products, i.e., yogurt, are frequently introduced at early stage as complementary food. Consumption of yogurt, kefir and other fermented dairy products are known for the health benefits mainly because of their probiotic effects on the gut flora (51). A systematic review summarized the beneficial findings of multiple studies performed in pediatric populations (0-24 months of age), discussed above, and it confirmed the hypothesis of the gut microbiota involvement to explain the improved diseases outcomes, particularly due to an increase in the Bifidobacteria genera (52). Animal studies have been performed to test the effect of fermented diary product on diabetes and cardiovascular biomarkers. A recent experimental obesity model showed improved insulin sensitivity and cardiometabolic risk factors in obese mice fed with Streptococcus-fermented milk or Greek-style yogurt, modulating the gut microbiota composition and the intestinal immune response (143). A second animal study on diabetic rats fed with yogurt fermented with Lactobacillus casei showed improved blood glucose and insulin level and reduced expression of genes involved in the liver gluconeogenesis, together with a shift in the microbiota composition and SCFA abundance (144). A human study testing the effect of fermented dairy on the Trimethylamine- $N$-oxide (TMAO) metabolites of the gut microbiota associated to the cardiovascular risk, demonstrated that healthy young men consuming yogurt or acidified milk for 2 weeks showed decreased levels of TMAO and different microbiome composition (145). To the best of our knowledge, no studies have been performed on the effect of fermented dairy in T1D subjects or animal models.

Complementary feeding is associated with a modification in the gut microbiota composition, influenced by proteins and fibers from solid foods. Non-digestible carbohydrates contained in solid foods provide substrates for the development of specific microbes (146). During the complementary feeding period, there is a reduction in Bifidobacteriaceae, Lactobacillaceae, Enterobacteriaceae, and Enterococcaceae and an increase of Clostridium coccoides, Lachnospiraceae, Ruminococcaceae, Bacteroidaceae, and Sutterellaceae (147, 148). However, Bifidobacteria, together with Bacteroides, remain among the prevalent species found in children's microbiota even after the introduction of complementary feeding (146). A recent study showed that the early introduction ( $<3$ months) of complementary food is associated with an altered microbial composition with a higher diversity and an accelerated maturation pattern (149). Increased fecal excretion of butyrate and other SCFAs is associated with both local and systemic effects. It is a sign of a reduced microbial diversity and an increased gut barrier permeability, and it is associated with systemic inflammation, hyperglycemia, dyslipidemia and an increased risk of developing obesity and hypertension (150). Moreover, the lower level of Bifidobacterium, which plays a key role in digesting oligosaccharides and producing vitamins and SCFAs, may also contribute to inflammation. Instead, the greater abundance of Akkermansia Muciniphila promotes an early growth of adult associated bacteria, impairing the growth of taxa typical of the developmental phase. Finally, the early introduction of food results in an increased concentration of fecal butyrate (149).

\section{Gluten and Cereals Modulate the Gut Microbiota in T1D}

A diet rich in fat and sugar like the "western diet" leads to an increase in Clostridium innocuum, Eubacterium dolichum, Catenibacterium mitsuokai, and Enterococcus spp. and a reduction in Bacteroides spp. (151). A carbohydrate-reduced diet or a low-caloric diet can revert the trend as observed in mice (152). The western diet also reduces the growth of other species such as Clostridium coccoides, Lactobacillus spp., and Bifidobacteria spp.; however, a diet rich in complex carbohydrates enhances the reduction of Mycobacterium avium subspecies and Enterobacteriaceae and the increase in Bifidobacteria spp. (153). Protein-rich diets can stimulate the activity of bacterial enzymes ( $\beta$-glucuronidase, azoreductase, and nitroreductase); this leads to the production of toxic metabolites that promote inflammation (154). On the contrary, the vegetarian diet, which is rich in 
fibers, stimulates the short chain fatty acids' production, causing a decrease in the intestinal $\mathrm{pH}$ and preventing the overgrowth of pathogenic bacteria $(104,155,156)$.

The link between dietary gluten and T1D is gaining the interest of researchers. The concomitant presence of T1D and celiac diseases is not rare ( $8 \%$ of coexistence) and it is challenging the clinicians with complex immunological and clinical management. At the date, the insulin and a gluten-free diet (GFD) are still the only recommended treatments for T1D and the celiac disease, respectively. However, these treatments pose certain challenges to both the clinicians and the patients, as GFD has a high glycemic index that affects the glycemic control. Moreover, intermittent gluten intake by these patients due to non-compliance with GFD stimulates the autoreactive immune cells which in turn result in an augmented immune response (157). A randomized controlled trial adopting GFD for 1 year on T1D and subclinical celiac disease patients, showed a decrease number of hypoglycemic episodes and a better glycemic control (158). Conversely, an observational case-control study on T1D and GFD-treated celiac patients compared with T1D alone showed that a long-term GFD does not affect the glycemic control, but it has a different impact on diabetes complications (159). The evidence is still unclear regarding the dietary approach for T1D and celiac patients, yet selected gluten free food high in fibers can better control the glycemia (160). Further studies and clinical trials are needed to test different types of GFD and gluten free foods. Moreover, other factors need to be included in the discussion such as the gut microbiota.

Concerning the role of gluten on the gut microbiota, no specific study has been conducted. However, in the latest years many studies have been published on the role of microbiome in the development of celiac disease (CD), resulting in heterogeneous data. Children affected by celiac disease have microbial dysbiosis, and this is thought to contribute to the pathogenesis of $\mathrm{CD}$. The function of Th17 cells, that play a role in the inflammatory response against gliadin peptides, is influenced by the microbiome (161). Children with $C D$ has a microbiome characterized by a higher amount of Proteobacteria, Bacteroides, Actinobacteria, Neisseria spp., and Haemophilus spp. and a lower abundance of Lactobacillus and Bifidobacterium (162). The gluten-free diet can restore the microbiome composition only partially and the reasons are obscure; a possible hypothesis could be the influence of genetic background on the microbial composition (163). Moreover, a gluten free diet in healthy subjects has been associated with a decrease of "healthy bacteria" (Bifidobacterium, Lactobacillus, Roseburia) and an increase of potentially unhealthy bacteria (Enterobacteriaceae, Clostridiaceae) (164). Therefore, based on the available data, it is not possible to draw any conclusion about the role of gluten on the T1D associated to gut microbiota changes.

The use of Bifidobacterium strains as probiotics showed a reduction in the gut inflammation and the production of proinflammatory cytokines which consequently improve the gut barrier's function. It was also demonstrated that probiotics can reduce the toxicity of gliadin by degrading the proinflammatory gluten peptides and reducing their immunogenicity (165).

\section{Micronutrients Intake and the Effect on the Gut Microbiota in T1D}

Micronutrients are able to interfere with the function of the microbiota (166). No studies investigated the effect of micronutrients deficiency on the gut microbiome of T1D patients. However, many evidences are available of the role of micronutrients in affecting microbiota in early life and in similar disease setting.

Vitamin D in particular plays a pivotal role in intestinal integrity, intestinal immunity and microbiome modulation in the autoimmune diseases, assuming a common mechanism of action affecting the immune response and the gut permeability (167). Microbial composition has been found affected by the season and directly correlated with vitamin D levels in Inflammatory Bowel Disease (IBD) patients (168). No data were found directly measuring the effect of vitamin D on gut microbiota of T1D patients, but we can speculate on similar mechanisms because of the frequent comorbidity of T1D and IBD (169).

Vitamin A and its receptor are involved in the response to pathogens modulating the response of IL-18 and IFN- $\gamma$ (170) and the gut microbiota composition (166), but no studies have been performed to investigate the effect of vitamin $\mathrm{A}$ on the infant microbiota of T1D patients. One study tested the effect of vitamin A supplementation within $48 \mathrm{~h}$ of life on healthy group of newborns and measured the effect on the gut microbiota at 615 weeks of life and later at 2 years of age. The authors found a difference between gender where the boys were more responsive to the treatment with increased abundance of the Bifidobacterium compared to the girls in early infancy, and instead girls at 2 years of life showed an increased level of Akkermansia (171), concluding on a potential contribution of vitamin $\mathrm{A}$ in the development of a heathy gut microflora.

SunGold kiwifruit, containing high levels of vitamin C, was tested on prediabetic people and the daily consumption over 12 weeks, even if it improved metabolic and anthropometric parameters, slightly impacted on the gut microbiota (172). An animal model was used to investigate the effect of antioxidant blends supplementation, including vitamin $\mathrm{C}$, in piglets at the weaning age. The supplementation was able to restore the unbalanced antioxidant capacity, the intestinal levels of Lactobacillus and Bifidobacterium and to reduce free radicals and levels of Escherichia coli caused by the early weaning stress (173).

Vitamin $\mathrm{E}$ and iron supplementation in a group of irondeficient infants and toddlers showed an increase of Roseburia compared to subjects supplemented with iron only (174). The effect of iron supplementation on the gut microbiota is not clear. Many studies have been performed with discrepant results due to different iron doses, chemical formula and administration routes (166).

Data on minerals and gut microbiota are also limited. Animal studies showed that the selenium supplementation increases the microbial diversity, and that the many species are seleniumdependent competing with the host on the selenium availability (175) and contributing to the metabolism of the seleno-proteins (176). Zinc and copper supplementation in pigs at the weaning age showed also decrease levels of Streptococcus, Enterobacter and 
TABLE 1 | Summary of the dietary factors affecting gut microbiota and their direct or indirect role in T1D.

\begin{tabular}{|c|c|c|c|}
\hline Dietary factors & Type of study & Findings & References \\
\hline \multirow[t]{2}{*}{ Breast milk } & $\begin{array}{l}\text { Human studies (T1D infants in the first } 3 \text { years } \\
\text { of life) }\end{array}$ & $\begin{array}{l}\text { Increased abundance of Bifidobacterium } \\
\text { inversely correlated with T1D risk }\end{array}$ & (126) \\
\hline & Human studies (infants at 2 weeks of life) & $\begin{array}{l}\text { Insulin and leptin hormones in the breast milk } \\
\text { increased microbial diversity and abundance of } \\
\text { Gammaproteobacteria }\end{array}$ & $(137)$ \\
\hline Formula milk & $\begin{array}{l}\text { Human clinical trials (infants 0-8 months of age } \\
\text { at risk of T1D) }\end{array}$ & $\begin{array}{l}\text { Positive association of Al with Bacteroides and } \\
\text { negative association with Roseburia }\end{array}$ & (142) \\
\hline Cow milk & Human studies (T1D children) & $\begin{array}{l}\text { Early introduction of cow milk association with } \\
\text { increased gut permeability }\end{array}$ & (14) \\
\hline Fermented milk products & Human study (infants 0-24 months of age) & Increase in the Bifidobacterium & (52) \\
\hline Complementary food & Human study (infants 0-12 months of age) & $\begin{array}{l}\text { Early introduction ( }<3 \text { months of life) was } \\
\text { associated with accelerated maturation and } \\
\text { higher diversity of the gut microbiota and } \\
\text { increased levels of SCFA }\end{array}$ & (149) \\
\hline \multirow[t]{4}{*}{ Gluten and Cereals } & $\begin{array}{l}\text { Randomized clinical trial on CD-T1D adult } \\
\text { patients }\end{array}$ & GFD improved glycemic control & (158) \\
\hline & $\begin{array}{l}\text { Observation case-control study on CD-T1D } \\
\text { adult patients }\end{array}$ & GFD affects diabetes complications & (159) \\
\hline & $\begin{array}{l}\text { Observational case-control study on CD } \\
\text { pediatric patients ( } 5 \text { years old) }\end{array}$ & GFD can partially restore microbiota & (163) \\
\hline & Clinical trial on healthy adults & $\begin{array}{l}\text { GFD decreases Bifidobacterium and } \\
\text { Lactobacillus, levels of SCFA and affect the } \\
\text { immune response }\end{array}$ & $(164)$ \\
\hline Vitamin A & $\begin{array}{l}\text { Interventional study on healthy newborns } \\
\text { (effects measured at } 6-15 \text { weeks and } 2 \text { years } \\
\text { of age) }\end{array}$ & $\begin{array}{l}\text { Increased levels of Bifidobacterium at 6-15 } \\
\text { weeks old boys; increased levels of Akkermasia } \\
\text { in } 2 \text { years old girls }\end{array}$ & $(171)$ \\
\hline \multirow[t]{2}{*}{ Vitamin C } & $\begin{array}{l}\text { Interventional study on prediabetic adult } \\
\text { population }\end{array}$ & $\begin{array}{l}\text { Improved metabolic parameters and slightly } \\
\text { affected microbiota }\end{array}$ & (172) \\
\hline & $\begin{array}{l}\text { Antioxidants supplementation on animal model } \\
\text { at weaning age }\end{array}$ & $\begin{array}{l}\text { Increased levels of Bifidobacterium and } \\
\text { Lactobacillus, reduced level of } E \text {. Coli, } \\
\text { improved antioxidant capacity }\end{array}$ & (173) \\
\hline Vitamins $\mathrm{C}$ and $\mathrm{E}$ & $\begin{array}{l}\text { Interventional study on T1D adolescents } \\
\text { (mean age } 12 \text { years old) }\end{array}$ & Improved endothelial function & (179) \\
\hline Vitamin $E$ and iron & $\begin{array}{l}\text { Interventional study on iron-deficient infants } \\
\text { and toddlers }\end{array}$ & Increased levels of Roseburia & (174) \\
\hline Zinc and Copper & $\begin{array}{l}\text { Supplementation on animal model at weaning } \\
\text { age }\end{array}$ & $\begin{array}{l}\text { Decreased levels od Streptococcus, } \\
\text { Enterobacter, Escherichia, increased levels of } \\
\text { Lachnospira and Roseburia }\end{array}$ & $(177)$ \\
\hline Probiotics & T1D animal model & $\begin{array}{l}\text { Lactobacillus johnsonii N6.2 induced a delay in } \\
\text { T1D onset, improved intestinal epithelial } \\
\text { function, reduced the inflammation, modulated } \\
\text { microbiota }\end{array}$ & (95) \\
\hline
\end{tabular}


TABLE 1 | Continued

\begin{tabular}{|c|c|c|c|}
\hline Dietary factors & Type of study & Findings & References \\
\hline & T1D animal model & $\begin{array}{l}\text { Lactobacillae-enriched probiotic VSL\#3 } \\
\text { decreased the risk of T1D, reduced amount of } \\
\text { Bacteroides, increased amounts of } \\
\text { Lactobacillae, Clostridia and Rikenellaceae, } \\
\text { improved immune response and intestinal } \\
\text { epithelial function }\end{array}$ & (93) \\
\hline & $\begin{array}{l}\text { Interventional studies on T1D infants } \\
\text { (0-6 months of life) }\end{array}$ & $\begin{array}{l}\text { No correlation of probiotic mixture } \\
\text { administration with the risk of islet Al and } \\
\text { diabetes progression }\end{array}$ & (181) \\
\hline Prebiotics & T1D animal model & $\begin{array}{l}\beta \text {-glucan supplementaion reduced levels of } \\
\text { Firmicutes increased Bacteroidetes, } \\
\text { Verrucomicrobia and } \\
\text { polysaccharide-fermenting bacteria, improved } \\
\text { carbohydrates metabolism, improvef immune } \\
\text { function, reduced insulitis degree }\end{array}$ & (184) \\
\hline Post-biotics & T1D animal model & $\begin{array}{l}\text { Protective role of SCFA, reduced Al, improved } \\
\text { immune function }\end{array}$ & (186) \\
\hline
\end{tabular}

Al, auto immunity; SCFA, short chain fatty acids; CD, celiac disease; GFD, Gluten-free diet.

Escherichia, and increased levels of Lachnospira and Roseburia (177). No studies are available on the effect of minerals on the gut microbiota of children affected by T1D, however there are clear evidences of micronutrients deficiencies in T1D adult population (178) and of the beneficial effect of antioxidant vitamins $\mathrm{C}$ and E on endothelial function in T1D cohort (179). Further studies are needed to investigate the effect of micronutrients deficiencies and potential supplementation during transition to solid foods to reduce the risk of T1D and its complications.

\section{PROBIOTICS/PREBIOTICS/POSTBIOTICS PROTECTIVE EFFECT AGAINST AUTOIMMUNITY}

Given the influence of altered microbiota in the development of the disease, an increasing number of studies evaluated the chance to modulate microbiota through dietary interventions or probiotic supplementation, in an attempt to induce a more tolerogenic environment and reduce the risk of islet autoimmunity and diabetes $(16,100)$.

Results from experimental studies and clinical trials support that the modulation of gut microbiota by probiotics administration may be protective toward T1D through several mechanisms: probiotics can increase the expression of junction and adhesion proteins, promote the barrier's function, reduce the oxidative stress and modulate the inflammatory response which lead to increased number of T-regulatory cells and anti-inflammatory cytokines (99). NOD mice supplemented with probiotics have a lower degree of insulitis (93). Another study, conducted in the USA on diabetic prone rats, showed that post-weaning administration of Lactobacillus johnsonii
N6.2 reduces or delays the onset of T1D, by influencing the microbiota, the intestinal proteins and the oxidative stress. Rats that received probiotics had lower IFN $\gamma$, INOs, and occluding, a higher amount of claudin, COX 2, and an increased expression of Globet cells. This leads to a reduction in the inflammation and the oxidative stress and an improvement in the intestinal barrier integrity. The same effect was not observed with the supplementation of Lactobacillus reuteri (95). An Italian study showed that supplementation with Lactobacillaceae-enriched probiotic VSL\#3, given alone or along with retinoic acid (RA), decreases the risk of developing diabetes in non-obese diabetic (NOD) mice (93). The microbiome profile of NOD mice supplemented with VLS\#3 is characterized by a reduced amount of Bacteroides and increased quantity of Lactobacillaceae, Clostridia (promoting FoxP3+ Treg cell differentiation in the intestinal mucosa) and Rikenellaceae. In addition, probiotic VLS\#3 reduces the expression of proinflammatory cytokine IL-1 $\beta$ and increases the production of pro-tolerogenic and immunomodulatory factors, such as indoleamine 2,3-dioxygenase (IDO) and IL- 33. Moreover, VLS\#3 stimulates the differentiation of tolerogenic dendritic cells $(\mathrm{CD} 103+)$ and limits the expansion and the differentiation of inflammatory T-cells (Th1 and Th17) in the intestinal tract, the spleen and the pancreatic lymph nodes. The combination of VLS\#3 with RA induces proliferation of T-regulatory cells in the intestinal mucosa. VLS3\# also increases the expression of zonulin-1 in the intestinal mucosa, promoting the integrity of the intestinal barrier (93). The TEDDY study showed that early probiotic administration ( $<27$ days of life) is associated with a reduced risk of islet autoimmunity compared to a later or any supplementation (180). By contrast, a Finnish study could not find any correlation between probiotic 


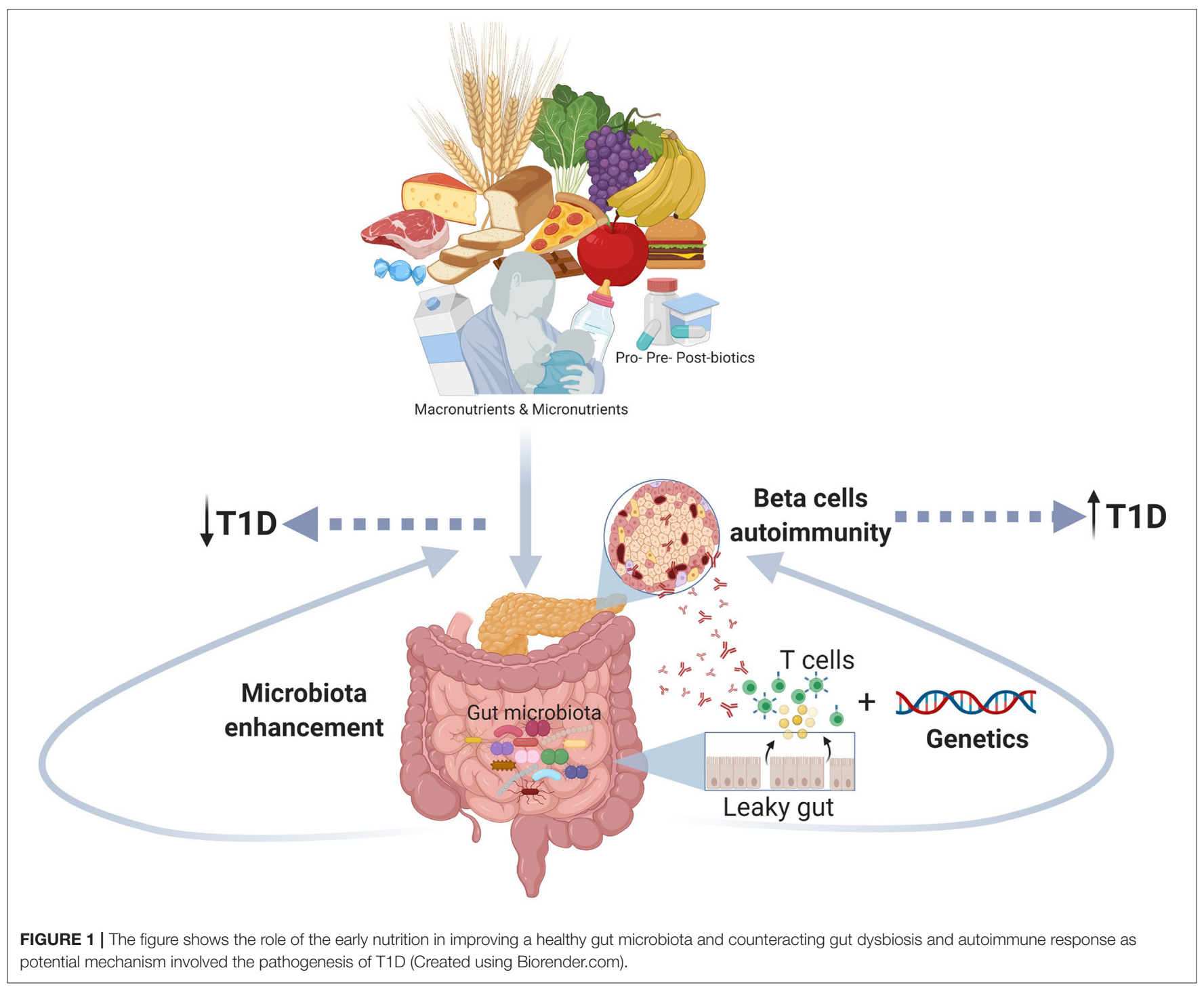

supplementation and the development of islet autoimmunity by 5 years, not even with T1D progression by 13 years (181). However, results from clinical trials depend on specific bacterial strains used as probiotic and cannot be applied to other species.

Prebiotics are non-digestible carbohydrates that can have a role in modulating the immune system and the gut microbiome, contributing to the development of autoimmune diseases such as T1D (182). Studies conducted on animals and humans showed a positive effect of prebiotics' supplementation on the microbiome and the immune system that can reduce intestinal permeability and inflammation, reducing the risk to develop T1D (183). A study conducted on NOD mice showed that long-term oral supplementation of low-dose $\beta$-glucan derived from yeast modifies the microbiota composition by reducing the amount of Firmicutes and increasing the abundance of Bacteroidetes phylum, Verrucomicrobia phylum and the polysaccharidefermenting bacteria. The $\beta$-glucan supplementation increases also some metabolic pathways, such as the carbohydrates metabolism and the glycan biosynthesis and metabolism. The use of this prebiotic has also an immunomodulatory effect, with an increased number of T-regulatory cells in the intestinal wall, favoring the development of immunotolerance, which reduces the degree of insulitis and the subsequent risk of developing T1D (184). A pilot study on T1D pediatric patients using administration of oligofructose-enriched inulin are ongoing, expecting to improve the glycemic control modulating the gut microbiota and the intestinal permeability (185). The immunomodulatory effect of prebiotics could lead to consider the possibility of introducing their supplementation in infants in order to reduce the risk of developing T1D.

A different strategy to prevent the development of autoimmunity and T1D can be the supplementation of microbial products (also known as post-biotics), such as SCFA, in order to modulate the microbiota and the immune system. The SCFAs (acetate, propionate and butyrate) have indeed an anti-inflammatory and immunomodulatory function. They promote the T-regulatory cells function, modulate cytokines' 
production, increase the expression of anti-microbial peptides, reduce oxidative stress and regulate the epithelial barrier function by increasing the expression of tight junction and the production of mucin (28). A study conducted on NOD mice confirmed the protective role of a combined acetate- and butyrate-yielding diet against diabetogenic pathways by decreasing the autoimmune response and boosting the function of regulatory $\mathrm{T}$ cells (186).

The probiotic, prebiotic and post-biotic therapeutic approach looks extremely interesting, but it still requires more clinical trials to confirm the efficacy and specificity of the treatment in T1D patients of different age groups, with different environment, diets and genetic backgrounds.

\section{CONCLUSIONS}

The T1D is a complex disorder with an unclear etiopathogenesis and an increased incidence in the last decades that presumes the contribution of multiple factors: genetics, age, environment, and diet. In this review, we focused our attention on the role of early diet as a modular of the gut microbiota and, indirectly, of the immune system (Table 1). We hypothesize a mechanism where long-term breastfeeding and avoiding early ( $<4$ months) introduction of solid foods, associated with a diet rich in micronutrients, contribute to developing healthy gut microbiota that boosts the maturation of the immune system and hence reduce the risk of T1D (Figure 1). The usage of probiotics, prebiotics and post-biotics in the prevention of T1D also gained great interest, yet it still requires further studies that will define the precise microbial profile of different types of patients (age,

\section{REFERENCES}

1. Saeedi P, Petersohn I, Salpea P, Malanda B, Karuranga S, Unwin $\mathrm{N}$, et al. Global and regional diabetes prevalence estimates for 2019 and projections for 2030 and 2045: results from the International Diabetes Federation Diabetes Atlas, 9th edition. Diabetes Res Clin Pract. (2019) 157:107843. doi: 10.1016/j.diabres.2019. 107843

2. Mobasseri M, Shirmohammadi M, Amiri T, Vahed N, Hosseini Fard H, Ghojazadeh M. Prevalence and incidence of type 1 diabetes in the world: a systematic review and meta-analysis. Health Promot Perspect. (2020) 10:98-115. doi: 10.34172/hpp.2020.18

3. Chellappan DK, Sivam NS, Teoh KX, Leong WP, Fui TZ, Chooi K, et al. Gene therapy and type 1 diabetes mellitus. Biomed Pharmacother. (2018) 108:1188-200. doi: 10.1016/j.biopha.2018.09.138

4. Ang GY. Age of onset of diabetes and all-cause mortality. World J Diabetes. (2020) 11:95-9. doi: 10.4239/wjd.v11.i4.95

5. Lawrence JM, Mayer-Davis EJ. What do we know about the trends in incidence of childhood-onset type 1 diabetes? Diabetologia. (2019) 62:370-2. doi: 10.1007/s00125-018-4791-z

6. Divers J, Mayer-Davis EJ, Lawrence JM, Isom S, Dabelea D, Dolan L, et al. Trends in incidence of type 1 and type 2 diabetes among youths-selected counties and Indian reservations, United States, 2002-2015. Morb Mortal Weekly Reprt. (2020) 69:161. doi: 10.15585/mmwr.mm6906a3

7. Regnell SE, Lernmark A.. Early prediction of autoimmune (type 1) diabetes. Diabetologia. (2017) 60:1370-81. doi: 10.1007/s00125-017-4308-1

8. Giwa AM, Ahmed R, Omidian Z, Majety N, Karakus KE, Omer SM, et al. Current understandings of the pathogenesis of type 1 diabetes: genetics to environment. World J Diabetes. (2020) 11:13. doi: 10.4239/wjd.v1 1.11 .13 ethnicity, environment, diet, etc.) and test the specific treatment of each type of T1D microbial profile.

The key messages from this paper are that promoting longterm breast-feeding during the first 6 months of life, avoiding early complementary foods and gluten introduction (before 4 months of age), and avoiding cow milk introduction before 12 months of life, may reduce the risk of developing T1D. The gut microbiota is affected by early nutrition, and the gut microbiota dysbiosis in infancy may contribute to the onset of T1D. Therefore, there is a need to plan randomized clinical trials testing the role of probiotics, prebiotics and post-biotics in T1D prevention.

\section{AUTHOR CONTRIBUTIONS}

AT and EV planned the manuscript and discussed the content. $\mathrm{CM}$ and $\mathrm{AP}$ wrote the introduction and about the clinical aspect of T1DM. SV and MA wrote the sections on early nutrition and probiotics. SA and FE wrote the microbiome sections and formatted the references. SA created the figure and formatted the final version of the manuscript. AT and EV reviewed and finalized the manuscript. GZ supervised and reviewed the manuscript. All Authors approved the submitted version of the manuscript.

\section{FUNDING}

The Sidra Medicine was supporting this work by internal research funds awarded to AT.
9. Bonifacio E, Hummel M, Walter M, Schmid S, Ziegler A-G. IDDM1 and multiple family history of type 1 diabetes combine to identify neonates at high risk for type 1 diabetes. Diabetes Care. (2004) 27:2695-700. doi: 10.2337/diacare.27.11.2695

10. Diaz-Valencia PA, Bougnères P, Valleron A-J. Global epidemiology of type 1 diabetes in young adults and adults: a systematic review. BMC Public Health. (2015) 15:255. doi: 10.1186/s12889-015-1591-y

11. DiMeglio LA, Evans-Molina C, Oram RA. Type 1 diabetes. Lancet. (2018) 391:2449-62. doi: 10.1016/S0140-6736(18)31320-5

12. Maahs DM, West NA, Lawrence JM, Mayer-Davis EJ. Epidemiology of type 1 diabetes. Endocrinol Metab Clin. (2010) 39:481-97. doi: 10.1016/j.ecl.2010.05.011

13. Catanzariti L, Faulks K, Moon L, Waters AM, Flack J, Craig M. Australia's national trends in the incidence of Type 1 diabetes in 0-14-year-olds, 2000-2006. Diabetic Med. (2009) 26:596-601. doi: 10.1111/j.1464-5491.2009.02737.x

14. Knip M, Virtanen SM, Åkerblom HK. Infant feeding and the risk of type 1 diabetes. Am J Clin Nutr. (2010) 91:1506S-3. doi: 10.3945/ajcn.2010.28701C

15. Knip M. Pathogenesis of type 1 diabetes: implications for incidence trends. Hormone Res Paediatr. (2011) 76 (Suppl. 1):57-64. doi: 10.1159/000329169

16. Penno MA, Couper JJ, Craig ME, Colman PG, Rawlinson WD, Cotterill $\mathrm{AM}$, et al. Environmental determinants of islet autoimmunity (ENDIA): a pregnancy to early life cohort study in children at-risk of type 1 diabetes. BMC Pediatrics. (2013) 13:124. doi: 10.1186/1471-2431-13-124

17. Gale E. Congenital rubella: citation virus or viral cause of type 1 diabetes? Diabetologia. (2008) 51:1559-66. doi: 10.1007/s00125-008-1099-4

18. Rešić Lindehammer S, Honkanen H, Nix WA, Oikarinen M, Lynch KF, Jönsson I, et al. Seroconversion to islet autoantibodies after enterovirus infection in early pregnancy. Viral Immunol. (2012) 25:254-61. doi: 10.1089/vim.2012.0022 
19. Rewers M, Ludvigsson J. Environmental risk factors for type 1 diabetes. Lancet. (2016) 387:2340-8. doi: 10.1016/S0140-6736(16)30507-4

20. Ferrara CT, Geyer SM, Liu Y-F, Evans-Molina C, Libman IM, Besser R, et al. Excess BMI in childhood: a modifiable risk factor for type 1 diabetes development? Diabetes Care. (2017) 40:698-701. doi: 10.2337/dc16-2331

21. Lamb MM, Miller M, Seifert JA, Frederiksen B, Kroehl M, Rewers M, et al. The effect of childhood cow's milk intake and HLA-DR genotype on risk of islet autoimmunity and type 1 diabetes: the diabetes autoimmunity study in the young. Pediatric Diabetes. (2015) 16:31-8. doi: 10.1111/pedi.12115

22. Virtanen SM. Dietary factors in the development of type 1 diabetes. Pediatric Diabetes. (2016) 17:49-55. doi: 10.1111/pedi.12341

23. Hakola L, Takkinen H-M, Niinistö S, Ahonen S, Nevalainen J, Veijola R, et al. Infant feeding in relation to the risk of advanced islet autoimmunity and type 1 diabetes in children with increased genetic susceptibility: a cohort study. Am J Epidemiol. (2018) 187:34-44. doi: 10.1093/aje/kwx191

24. Victora CG, Bahl R, Barros AJ, França GV, Horton S, Krasevec J, et al. Breastfeeding in the 21st century: epidemiology, mechanisms, and lifelong effect. Lancet. (2016) 387:475-90. doi: 10.1016/S0140-6736(15)01024-7

25. Lund-Blix NA, Sander SD, Størdal K, Andersen A-MN, Rønningen KS, Joner $\mathrm{G}$, et al. Infant feeding and risk of type 1 diabetes in two large Scandinavian birth cohorts. Diabetes Care. (2017) 40:920-7. doi: 10.2337/dc17-0016

26. Cardwell CR, Stene LC, Ludvigsson J, Rosenbauer J, Cinek O, Svensson J, et al. Breast-feeding and childhood-onset type 1 diabetes: a pooled analysis of individual participant data from 43 observational studies. Diabetes Care. (2012) 35:2215-25. doi: 10.2337/dc12-0438

27. Virtanen SM, Kenward MG, Erkkola M, Kautiainen S, Kronberg-Kippilä C, Hakulinen T, et al. Age at introduction of new foods and advanced beta cell autoimmunity in young children with HLA-conferred susceptibility to type 1 diabetes. Diabetologia. (2006) 49:1512-21. doi: 10.1007/s00125-0060236-1

28. Xiao L, van't Land B, van de Worp WR, Stahl B, Folkerts G, Garssen J. Early-life nutritional factors and mucosal immunity in the development of autoimmune diabetes. Front Immunol. (2017) 8:1219. doi: 10.3389/fimmu.2017.01219

29. Xiao L, van't Land B, Engen PA, Naqib A, Green SJ, Nato A, et al. Human milk oligosaccharides protect against the development of autoimmune diabetes in NOD-mice. Sci Rep. (2018) 8:3829. doi: 10.1038/s41598-018-22052-y

30. Pereira PF, Rita de Cássia GA, Araújo RMA. Does breastfeeding influence the risk of developing diabetes mellitus in children? a review of current evidence. J Pediatria. (2014) 90:7-15. doi: 10.1016/j.jpedp.2013.02.010

31. Brugman S, Visser J, Hillebrands J-L, Bos N, Rozing J. Prolonged exclusive breastfeeding reduces autoimmune diabetes incidence and increases regulatory T-cell frequency in bio-breeding diabetes-prone rats. Diabetes. (2009) 25:380-7. doi: 10.1002/dmrr.953

32. Ojo-Okunola A, Nicol M, Du Toit E. Human breast milk bacteriome in health and disease. Nutrients. (2018) 10:1643. doi: 10.3390/nu10111643

33. Heikkilä MP, Saris P. Inhibition of Staphylococcus aureus by the commensal bacteria of human milk. J Appl Microbiol. (2003) 95:471-8. doi: 10.1046/j.1365-2672.2003.02002.x

34. Olivares M, Díaz-Ropero M, Martín R, Rodríguez J, Xaus J. Antimicrobial potential of four Lactobacillus strains isolated from breast milk. J Appl Microbiol. (2006) 101:72-9. doi: 10.1111/j.1365-2672.2006.02981.x

35. Perez-Cano FJ, Dong H, Yaqoob P. In vitro immunomodulatory activity of Lactobacillus fermentum CECT5716 and Lactobacillus salivarius CECT5713: two probiotic strains isolated from human breast milk. Immunobiology. (2010) 215:996-1004. doi: 10.1016/j.imbio.2010.01.004

36. Niinistö S, Takkinen H-M, Erlund I, Ahonen S, Toppari J, Ilonen J, et al. Fatty acid status in infancy is associated with the risk of type 1 diabetes-associated autoimmunity. Diabetologia. (2017) 60:1223-33. doi: $10.1007 /$ s00125-017-4280-9

37. World Health Orgnization (WHO). Breastfeeding. (2018). Available online at: https://www.who.int/health-topics/breastfeeding\#tab=tab_1.

38. Fewtrell M, Bronsky J, Campoy C, Domellöf M, Embleton N, Mis NF, et al. Complementary feeding: a position paper by the European Society for Paediatric Gastroenterology, Hepatology, and Nutrition (ESPGHAN) committee on nutrition. J Pediatric Gastroenterol Nutr. (2017) 64:119-32. doi: 10.1097/MPG.0000000000001454
39. Szajewska H, Shamir R, Chmielewska A, Pieścik-Lech M, Auricchio R, Ivarsson A, et al. Systematic review with meta-analysis: early infant feeding and coeliac disease-update 2015. Aliment Pharmacol Therapeutics. (2015) 41:1038-54. doi: 10.1111/apt.13163

40. Virtanen SM, Nevalainen J, Kronberg-Kippila C, Ahonen S, Tapanainen $\mathrm{H}$, Uusitalo L, et al. Food consumption and advanced beta cell autoimmunity in young children with HLA-conferred susceptibility to type 1 diabetes: a nested case-control design. Am J Clin Nutr. (2012) 95:471-8. doi: 10.3945/ajen.111.018879

41. Rosenbauer J, Herzig P, Giani G. Early infant feeding and risk of type 1 diabetes mellitus-a nationwide population-based case-control study in pre-school children. Diabetes Metab Res Rev. (2008) 24:211-22. doi: $10.1002 / \mathrm{dmrr} .791$

42. Knip M, Åkerblom HK, Al Taji E, Becker D, Bruining J, Castano L, et al. Effect of hydrolyzed infant formula vs conventional formula on risk of type 1 diabetes: the trigr randomized clinical trial. JAMA. (2018) 319:38-48. doi: 10.1001/jama.2017.19826

43. Hummel S, Beyerlein A, Tamura R, Uusitalo U, Aronsson CA, Yang J, et al. First infant formula type and risk of islet autoimmunity in The Environmental Determinants of Diabetes in the Young (TEDDY) study. Diabetes Care. (2017) 40:398-404. doi: 10.2337/dc16-1624

44. Fiocchi A, Brozek J, Schünemann H, Bahna SL, von Berg A, Beyer K, et al. World Allergy Organization (WAO) Diagnosis and Rationale for Action against Cow's Milk Allergy (DRACMA) guidelines. Pediatr Allergy Immunol. (2010) 21:1-125. doi: 10.1111/j.1399-3038.2010.01068.x

45. Wahlberg J, Vaarala O, Ludvigsson J. Dietary risk factors for the emergence of type 1 diabetes-related autoantibodies in 21/2 year-old Swedish children. Br J Nutr. (2006) 95:603-8. doi: 10.1079/BJN20051676

46. Sipetić S, Vlajinac H, Kocev N, Bjekić M, Sajic S. Early infant diet and risk of type 1 diabetes mellitus in Belgrade children. Nutrition. (2005) 21:474-9. doi: 10.1016/j.nut.2004.07.014

47. Kagohashi Y, Otani $\mathrm{H}$. Role of nutritional factors at the early life stages in the pathogenesis and clinical course of type 1 diabetes. Biomed Res Int. (2015) 2015:382165. doi: 10.1155/2015/382165

48. Vaarala O, Knip M, Paronen J, Hämäläinen AM, Muona P, Väätäinen M, et al. Cow's milk formula feeding induces primary immunization to insulin in infants at genetic risk for type 1 diabetes. Diabetes. (1999) 48:1389-94. doi: $10.2337 /$ diabetes.48.7.1389

49. Westerholm-Ormio M, Vaarala O, Pihkala P, Ilonen J, Savilahti E. Immunologic activity in the small intestinal mucosa of pediatric patients with type 1 diabetes. Diabetes. (2003) 52:2287. doi: $10.2337 /$ diabetes.52.9.2287

50. Li X, Atkinson MA. The role for gut permeability in the pathogenesis of type 1 diabetes-a solid or leaky concept? Pediatric Diabetes. (2015) 16:485-92. doi: $10.1111 /$ pedi.12305

51. Kok CR, Hutkins R. Yogurt and other fermented foods as sources of health-promoting bacteria. Nutr Rev. (2018) 76 (Suppl. 1):4-15. doi: 10.1093/nutrit/nuy056

52. Donovan SM, Rao G. Health benefits of yogurt among infants and toddlers aged 4 to 24 months: a systematic review. Nutr Rev. (2019) 77:478-86. doi: 10.1093/nutrit/nuz009

53. Scott FW, Rowsell P, Wang GS, Burghardt K, Kolb H, Flohé S. Oral exposure to diabetes-promoting food or immunomodulators in neonates alters gut cytokines and diabetes. Diabetes. (2002) 51:73-8. doi: 10.2337/diabetes.51.1.73

54. Funda DP, Kaas A, Bock T, Tlaskalová-Hogenová H, Buschard K. Gluten-free diet prevents diabetes in NOD mice. Diabetes Metab Res Rev. (1999) 15:323-7. doi: 10.1002/(sici)1520-7560(199909/10) 15:5<323::aid-dmrr53>3.0.co;2-p

55. Antvorskov JC, Josefsen K, Engkilde K, Funda DP, Buschard K. Dietary gluten and the development of type 1 diabetes. Diabetologia. (2014) 57:1770-80. doi: 10.1007/s00125-014-3265-1

56. Lund-Blix NA, Dong F, Mårild K, Seifert J, Barón AE, Waugh KC, et al. Gluten intake and risk of islet autoimmunity and progression to type 1 diabetes in children at increased risk of the disease: the Diabetes Autoimmunity Study in the Young (DAISY). Diabetes Care. (2019) 42:78996. doi: $10.2337 / \mathrm{dc} 18-2315$ 
57. Beyerlein A, Chmiel R, Hummel S, Winkler C, Bonifacio E, Ziegler AG. Timing of gluten introduction and islet autoimmunity in young children: updated results from the BABYDIET study. Diabetes Care. (2014) 37:e194-5. doi: $10.2337 / \mathrm{dc} 14-1208$

58. Szajewska H, Shamir R, Mearin L, Ribes-Koninckx C, Catassi C, Domellöf $\mathrm{M}$, et al. Gluten introduction and the risk of coeliac disease: a position paper by the European society for pediatric gastroenterology, hepatology, and nutrition. J Pediatr Gastroenterol Nutr. (2016) 62:507-13. doi: 10.1097/MPG.0000000000001105

59. Hakola L, Miettinen ME, Syrjälä E, Åkerlund M, Takkinen H-M, Korhonen TE, et al. Association of cereal, gluten, and dietary fiber intake with islet autoimmunity and type 1 diabetes. JAMA Pediatrics. (2019) 173:953-60. doi: 10.1001/jamapediatrics.2019.2564

60. Andren Aronsson C, Lee HS, Hard Af Segerstad EM, Uusitalo U, Yang J, Koletzko S, et al. Association of gluten intake during the first 5 years of life with incidence of celiac disease autoimmunity and celiac disease among children at increased risk. JAMA. (2019) 322:514-23. doi: 10.1001/jama.2019.10329

61. Charoenngam N, Holick MF. Immunologic effects of vitamin D on human health and disease. Nutrients. (2020) 12:2097. doi: 10.3390/nu120 72097

62. Norris JM, Lee H-S, Frederiksen B, Erlund I, Uusitalo U, Yang $\mathrm{J}$, et al. Plasma 25-hydroxyvitamin D concentration and risk of islet autoimmunity. Diabetes. (2018) 67:146-54. doi: 10.2337/db170802

63. Raab J, Giannopoulou EZ, Schneider S, Warncke K, Krasmann M, Winkler $\mathrm{C}$, et al. Prevalence of vitamin D deficiency in pre-type 1 diabetes and its association with disease progression. Diabetologia. (2014) 57:902-8. doi: 10.1007/s00125-014-3181-4

64. Mäkinen M, Mykkänen J, Koskinen M, Simell V, Veijola R, Hyöty H, et al. Serum 25-hydroxyvitamin D concentrations in children progressing to autoimmunity and clinical type 1 diabetes. J Clin Endocrinol Metab. (2016) 101:723-9. doi: 10.1210/jc.2015-3504

65. Simpson M, Brady H, Yin X, Seifert J, Barriga K, Hoffman M, et al. No association of vitamin D intake or 25-hydroxyvitamin D levels in childhood with risk of islet autoimmunity and type 1 diabetes: the Diabetes Autoimmunity Study in the Young (DAISY). Diabetologia. (2011) 54:2779. doi: 10.1007/s00125-011-2278-2

66. Dong J-Y, Zhang W, Chen JJ, Zhang Z-L, Han S-F, Qin L-Q. Vitamin D intake and risk of type 1 diabetes: a meta-analysis of observational studies. Nutrients. (2013) 5:3551-62. doi: 10.3390/nu5093551

67. Gregoriou E, Mamais I, Tzanetakou I, Lavranos G, Chrysostomou S. The effects of vitamin D supplementation in newly diagnosed type 1 diabetes patients: systematic review of randomized controlled trials. Rev Diabet Stud. (2017) 14:260. doi: 10.1900/RDS.2017.14.260

68. Yosaee S, Fakhrabadi MA, Shidfar F. Positive evidence for vitamin A role in prevention of type 1 diabetes. World J Diabetes. (2016) 7:177. doi: 10.4239/wjd.v7.i9.177

69. Mattila M, Erlund I, Lee H-S, Niinistö S, Uusitalo U, Aronsson CA, et al. Plasma ascorbic acid and the risk of islet autoimmunity and type 1 diabetes: the TEDDY study. Diabetologia. (2020) 63:278-86. doi: 10.1007/s00125-019-05028-z

70. Jablonska E, Reszka E, Gromadzinska J, Wieczorek E, Krol MB, Raimondi S, et al. The effect of selenium supplementation on glucose homeostasis and the expression of genes related to glucose metabolism. Nutrients. (2016) 8:772. doi: $10.3390 /$ nu8120772

71. Özenç S, Saldir M, Sari E, Çetinkaya S, Yeşilkaya S, Babacan O, et al. Selenium, zinc, and copper levels and their relation with HbAlc status in children with type 1 diabetes mellitus. Int J Diabetes Dev Countr. (2015) 35:514-8. doi: 10.1007/s13410-015-0327-y

72. Moltchanova E, Rytkönen M, Kousa A, Taskinen O, Tuomilehto J, Karvonen for the Spat Study Group M. Zinc and nitrate in the ground water and the incidence of type 1 diabetes in Finland. Diabet Med. (2004) 21:256-61. doi: 10.1111/j.1464-5491.2004.01125.x

73. Valera P, Zavattari P, Sanna A, Pretti S, Marcello A, Mannu C, et al. Zinc and other metals deficiencies and risk of type 1 diabetes: an ecological study in the high risk Sardinia island. PLOS ONE. (2015) 10:e0141262. doi: 10.1371 /journal.pone. 0141262
74. Purchiaroni F, Tortora A, Gabrielli M, Bertucci F, Gigante G, Ianiro G, et al. The role of intestinal microbiota and the immune system. Eur Rev Med Pharmacol Sci. (2013) 17:323-33.

75. Martin R, Nauta AJ, Ben Amor K, Knippels LM, Knol J, Garssen J. Early life: gut microbiota and immune development in infancy. Benef Microbes. (2010) 1:367-82. doi: 10.3920/BM2010.0027

76. Hansen CHF, Nielsen DS, Kverka M, Zakostelska Z, Klimesova K, Hudcovic $\mathrm{T}$, et al. Patterns of early gut colonization shape future immune responses of the host. PLoS ONE. (2012) 7:e34043. doi: 10.1371/journal.pone.0034043

77. Mulder IE, Schmidt B, Lewis M, Delday M, Stokes CR, Bailey M, et al. Restricting microbial exposure in early life negates the immune benefits associated with gut colonization in environments of high microbial diversity. PLoS ONE. (2011) 6:e28279. doi: 10.1371/journal.pone.0028279

78. Olszak T, An D, Zeissig S, Vera MP, Richter J, Franke A, et al. Microbial exposure during early life has persistent effects on natural killer $\mathrm{T}$ cell function. Science. (2012) 336:489-93. doi: 10.1126/science.1219328

79. Sudo N, Chida Y, Aiba Y, Sonoda J, Oyama N, Yu X-N, et al. Postnatal microbial colonization programs the hypothalamic-pituitary-adrenal system for stress response in mice. J Physiol. (2004) 558(Pt. 1):263-75. doi: 10.1113/jphysiol.2004.063388

80. Thursby E, Juge N. Introduction to the human gut microbiota. Biochem J. (2017) 474:1823-36. doi: 10.1042/BCJ20160510

81. Lederberg J, McCray AT. Ome SweetOmics-A genealogical treasury of words. Scientist. (2001) 15:8.

82. Marchesi JR, Ravel J. The vocabulary of microbiome research: a proposal. Microbiome. (2015) 3:31. doi: 10.1186/s40168-015-0094-5

83. Ursell LK, Metcalf JL, Parfrey LW, Knight R. Defining the human microbiome. Nutrition reviews. (2012) 70:S38-44. doi: 10.1111/j.1753-4887.2012.00493.x

84. Auricchio R, Paparo F, Maglio M, Franzese A, Lombardi F, Valerio G, et al. In vitro-deranged intestinal immune response to gliadin in type 1 diabetes. Diabetes. (2004) 53:1680. doi: 10.2337/diabetes.53.7.1680

85. Bosi E, Molteni L, Radaelli MG, Folini L, Fermo I, Bazzigaluppi E, et al. Increased intestinal permeability precedes clinical onset of type 1 diabetes. Diabetologia. (2006) 49:2824-7. doi: 10.1007/s00125-006-0465-3

86. Vaarala O. Leaking gut in type 1 diabetes. Curr Opin Gastroenterol. (2008) 24:701-6. doi: 10.1097/MOG.0b013e32830e6d98

87. Luopajärvi K, Savilahti E, Virtanen SM, Ilonen J, Knip M, Akerblom HK, et al. Enhanced levels of cow's milk antibodies in infancy in children who develop type 1 diabetes later in childhood. Pediatr Diabetes. (2008) 9:434-41. doi: 10.1111/j.1399-5448.2008.00413.x

88. Wen L, Ley RE, Volchkov PY, Stranges PB, Avanesyan L, Stonebraker AC, et al. Innate immunity and intestinal microbiota in the development of Type 1 diabetes. Nature. (2008) 455:1109-13. doi: 10.1038/nature07336

89. Candon S, Perez-Arroyo A, Marquet C, Valette F, Foray A-P, Pelletier $\mathrm{B}$, et al. Correction: antibiotics in early life alter the gut microbiome and increase disease incidence in a spontaneous mouse model of autoimmune insulin-dependent diabetes. PLoS ONE. (2016) 11:e0147888. doi: 10.1371/journal.pone.0147888

90. Livanos AE, Greiner TU, Vangay P, Pathmasiri W, Stewart D, McRitchie $\mathrm{S}$, et al. Antibiotic-mediated gut microbiome perturbation accelerates development of type 1 diabetes in mice. Nat Microbiol. (2016) 1:16140. doi: 10.1038/nmicrobiol.2016.140

91. Hansen CH, Krych L, Nielsen DS, Vogensen FK, Hansen LH, Sørensen SJ, et al. Early life treatment with vancomycin propagates Akkermansia muciniphila and reduces diabetes incidence in the NOD mouse. Diabetologia. (2012) 55:2285-94. doi: 10.1007/s00125-012-2564-7

92. Calcinaro F, Dionisi S, Marinaro M, Candeloro P, Bonato V, Marzotti $\mathrm{S}$, et al. Oral probiotic administration induces interleukin-10 production and prevents spontaneous autoimmune diabetes in the non-obese diabetic mouse. Diabetologia. (2005) 48:1565-75. doi: 10.1007/s00125-005-1831-2

93. Dolpady J, Sorini C, Di Pietro C, Cosorich I, Ferrarese R, Saita $\mathrm{D}$, et al. Oral probiotic VSL\#3 prevents autoimmune diabetes by modulating microbiota and promoting indoleamine 2,3-dioxygenaseenriched tolerogenic intestinal environment. J Diabetes Res. (2016) 2016:7569431. doi: 10.1155/2016/7569431

94. Jia L, Shan K, Pan L-L, Feng N, Lv Z, Sun Y, et al. Clostridium butyricum CGMCC0313.1 protects against autoimmune diabetes by modulating 
intestinal immune homeostasis and inducing pancreatic regulatory $\mathrm{T}$ cells. Front Immunol. (2017) 8:1345. doi: 10.3389/fimmu.2017.01345

95. Valladares R, Sankar D, Li N, Williams E, Lai K-K, Abdelgeliel AS, et al. Lactobacillus johnsonii N6.2 mitigates the development of type 1 diabetes in BB-DP rats. PLoS ONE. (2010) 5:e10507. doi: 10.1371/journal.pone.0010507

96. Harbison JE, Roth-Schulze AJ, Giles LC, Tran CD, Ngui KM, Penno MA, et al. Gut microbiome dysbiosis and increased intestinal permeability in children with islet autoimmunity and type 1 diabetes: a prospective cohort study. Pediatr Diabetes. (2019) 20:574-83. doi: 10.1111/pedi.12865

97. Pellegrini S, Sordi V, Bolla AM, Saita D, Ferrarese R, Canducci F, et al. Duodenal mucosa of patients with type 1 diabetes shows distinctive inflammatory profile and microbiota. J Clin Endocrinol Metab. (2017) 102:1468-77. doi: 10.1210/jc.2016-3222

98. Leiva-Gea I, Sánchez-Alcoholado L, Martín-Tejedor B, Castellano-Castillo D, Moreno-Indias I, Urda-Cardona A, et al. Gut microbiota differs in composition and functionality between children with type 1 diabetes and MODY2 and healthy control subjects: a case-control study. Diabetes Care. (2018) 41:2385-95. doi: 10.2337/dc18-0253

99. Gomes AC, Bueno AA, de Souza RGM, Mota JF. Gut microbiota, probiotics and diabetes. Nutr J. (2014) 13:60. doi: 10.1186/1475-2891-13-60

100. de Oliveira GLV, Leite AZ, Higuchi BS, Gonzaga MI, Mariano VS. Intestinal dysbiosis and probiotic applications in autoimmune diseases. Immunology. (2017) 152:1-12. doi: 10.1111/imm.12765

101. Marietta E, Horwath I, Balakrishnan B, Taneja V. Role of the intestinal microbiome in autoimmune diseases and its use in treatments. Cell Immunol. (2019) 339:50-8. doi: 10.1016/j.cellimm.2018.10.005

102. Davis-Richardson AG, Ardissone AN, Dias R, Simell V, Leonard MT, Kemppainen KM, et al. Bacteroides dorei dominates gut microbiome prior to autoimmunity in Finnish children at high risk for type 1 diabetes. Front Microbiol. (2014) 5:678. doi: 10.3389/fmicb.2014.00678

103. Giongo A, Gano KA, Crabb DB, Mukherjee N, Novelo LL, Casella G, et al. Toward defining the autoimmune microbiome for type 1 diabetes. ISME J. (2011) 5:82-91. doi: 10.1038/ismej.2010.92

104. Brown K, DeCoffe D, Molcan E, Gibson DL. Diet-induced dysbiosis of the intestinal microbiota and the effects on immunity and disease. Nutrients. (2012) 4:1095-119. doi: 10.3390/nu4081095

105. Vatanen T, Franzosa EA, Schwager R, Tripathi S, Arthur TD, Vehik K, et al. The human gut microbiome in early-onset type 1 diabetes from the TEDDY study. Nature. (2018) 562:589-94. doi: 10.1038/s41586-018-0620-2

106. Costa FR, Françozo MC, de Oliveira GG, Ignacio A, Castoldi A, Zamboni DS, et al. Gut microbiota translocation to the pancreatic lymph nodes triggers NOD2 activation and contributes to T1D onset. J Exp Med. (2016) 213:1223-39. doi: 10.1084/jem.20150744

107. Hänninen A, Nurmela R, Maksimow M, Heino J, Jalkanen S, Kurts C. Islet beta-cell-specific $\mathrm{T}$ cells can use different homing mechanisms to infiltrate and destroy pancreatic islets. Am J Pathol. (2007) 170:240-50. doi: 10.2353 /ajpath.2007.060142

108. Kolodziejczyk AA, Zheng D, Elinav E. Diet-microbiota interactions and personalized nutrition. Nat Rev Microbiol. (2019) 17:742-53. doi: 10.1038/s41579-019-0256-8

109. Wu GD, Chen J, Hoffmann C, Bittinger K, Chen Y-Y, Keilbaugh SA, et al. Linking long-term dietary patterns with gut microbial enterotypes. Science. (2011) 334:105-8. doi: 10.1126/science.1208344

110. Mejía-León ME, Petrosino JF, Ajami NJ, Domínguez-Bello MG, de la Barca AM. Fecal microbiota imbalance in Mexican children with type 1 diabetes. Sci Rep. (2014) 4:3814. doi: 10.1038/srep03814

111. Murri M, Leiva I, Gomez-Zumaquero JM, Tinahones FJ, Cardona F, Soriguer $\mathrm{F}$, et al. Gut microbiota in children with type 1 diabetes differs from that in healthy children: a case-control study. BMC Med. (2013) 11:46. doi: 10.1186/1741-7015-11-46

112. Fava F, Gitau R, Griffin BA, Gibson GR, Tuohy KM, Lovegrove JA. The type and quantity of dietary fat and carbohydrate alter faecal microbiome and short-chain fatty acid excretion in a metabolic syndrome 'at-risk' population. Int J Obes. (2013) 37:216-23. doi: 10.1038/ijo.2012.33

113. LeBlanc JG, Milani C, de Giori GS, Sesma F, van Sinderen D, Ventura M. Bacteria as vitamin suppliers to their host: a gut microbiota perspective. Curr Opin Biotechnol. (2013) 24:160-8. doi: 10.1016/j.copbio.2012.08.005
114. Magnúsdóttir S, Ravcheev D, de Crécy-Lagard V, Thiele I. Systematic genome assessment of B-vitamin biosynthesis suggests co-operation among gut microbes. Front Genet. (2015) 6:148. doi: 10.3389/fgene.2015.00148

115. Tan J, McKenzie C, Potamitis M, Thorburn AN, Mackay CR, Macia L. The role of short-chain fatty acids in health and disease. Adv Immunol. (2014) 121:91-119. doi: 10.1016/B978-0-12-800100-4.00003-9

116. Morrison DJ, Preston T. Formation of short chain fatty acids by the gut microbiota and their impact on human metabolism. Gut Microbes. (2016) 7:189-200. doi: 10.1080/19490976.2015.1134082

117. van der Beek CM, Dejong CHC, Troost FJ, Masclee AAM, Lenaerts K. Role of short-chain fatty acids in colonic inflammation, carcinogenesis, and mucosal protection and healing. Nutr Rev. (2017) 75:286-305. doi: 10.1093/nutrit/nuw067

118. Keszthelyi D, Troost FJ, Masclee AA. Understanding the role of tryptophan and serotonin metabolism in gastrointestinal function. Neurogastroenterol Motil. (2009) 21:1239-49. doi: 10.1111/j.1365-2982.2009.01370.x

119. Kiss EA, Vonarbourg C, Kopfmann S, Hobeika E, Finke D, Esser C, et al. Natural aryl hydrocarbon receptor ligands control organogenesis of intestinal lymphoid follicles. Science. (2011) 334:1561-5. doi: 10.1126/science.1214914

120. Ridlon JM, Kang DJ, Hylemon PB. Bile salt biotransformations by human intestinal bacteria. J Lipid Res. (2006) 47:241-59. doi: 10.1194/jlr.R500013-JLR200

121. Li N, Hatch $\mathrm{M}$, Wasserfall $\mathrm{CH}$, Douglas-Escobar M, Atkinson MA, Schatz DA, et al. Butyrate and type 1 diabetes mellitus: can we fix the intestinal leak? J Pediatr Gastroenterol Nutr. (2010) 51:414-7. doi: 10.1097/MPG.0b013e3181dd913a

122. Nagpal R, Yamashiro Y. Gut microbiota composition in healthy japanese infants and young adults born by C-section. Ann Nutr Metab. (2018) 73 (Suppl. 3):4-11. doi: 10.1159/000490841

123. Hansen R, Scott KP, Khan S, Martin JC, Berry SH, Stevenson M, et al. First-pass meconium samples from healthy term vaginally-delivered neonates: an analysis of the microbiota. PLoS ONE. (2015) 10:e0133320. doi: 10.1371/journal.pone. 0133320

124. Martin R, Makino H, Cetinyurek Yavuz A, Ben-Amor K, Roelofs M, Ishikawa E, et al. Early-life events, including mode of delivery and type of feeding, siblings and gender, shape the developing gut microbiota. PLoS ONE. (2016) 11:e0158498. doi: 10.1371/journal.pone.0158498

125. Pannaraj PS, Li F, Cerini C, Bender JM, Yang S, Rollie A, et al. Association between breast milk bacterial communities and establishment and development of the infant gut microbiome. JAMA Pediatr. (2017) 171:647-54. doi: 10.1001/jamapediatrics.2017.0378

126. Insel R, Knip M. Prospects for primary prevention of type 1 diabetes by restoring a disappearing microbe. Pediatr Diabetes. (2018) 19:1400-6. doi: $10.1111 /$ pedi.12756

127. Schroeder BO, Birchenough GMH, Ståhlman M, Arike L, Johansson MEV, Hansson GC, et al. Bifidobacteria or fiber protects against diet-induced microbiota-mediated colonic mucus deterioration. Cell Host Microbe. (2018) 23:27-40.e7. doi: 10.1016/j.chom.2017.11.004

128. Dedrick S, Sundaresh B, Huang Q, Brady C, Yoo T, Cronin C, et al. The role of gut microbiota and environmental factors in type 1 diabetes pathogenesis. Front Endocrinol. (2020) 11:78. doi: 10.3389/fendo.2020.00078

129. Balmer SE, Wharton BA. Diet and faecal flora in the newborn: breast milk and infant formula. Arch Dis Child. (1989) 64:1672-7. doi: 10.1136/adc.64.12.1672

130. Stark PL, Lee A. The microbial ecology of the large bowel of breast-fed and formula-fed infants during the first year of life. J Med Microbiol. (1982) 15:189-203. doi: 10.1099/00222615-15-2-189

131. Bezirtzoglou E, Tsiotsias A, Welling GW. Microbiota profile in feces of breast- and formula-fed newborns by using fluorescence in situ hybridization (FISH). Anaerobe. (2011) 17:478-82. doi: 10.1016/j.anaerobe.2011.03.009

132. Bäckhed F, Roswall J, Peng Y, Feng Q, Jia H, Kovatcheva-Datchary $\mathrm{P}$, et al. Dynamics and stabilization of the human gut microbiome during the first year of life. Cell Host Microbe. (2015) 17:690-703. doi: 10.1016/j.chom.2015.04.004

133. Penders J, Vink C, Driessen C, London N, Thijs C, Stobberingh EE. Quantification of Bifidobacterium spp., Escherichia coli and 
Clostridium difficile in faecal samples of breast-fed and formulafed infants by real-time PCR. FEMS Microbiol Lett. (2005) 243:141-7. doi: 10.1016/j.femsle.2004.11.052

134. Davis MY, Zhang H, Brannan LE, Carman RJ, Boone JH. Rapid change of fecal microbiome and disappearance of Clostridium difficile in a colonized infant after transition from breast milk to cow milk. Microbiome. (2016) 4:53. doi: 10.1186/s40168-016-0198-6

135. Fassatoui M, Lopez-Siles M, Díaz-Rizzolo DA, Jmel H, Naouali C, Abdessalem G, et al. Gut microbiota imbalances in Tunisian participants with type 1 and type 2 diabetes mellitus. Biosci Rep. (2019) 39:BSR20182348. doi: 10.1042/BSR20182348

136. Stewart CJ, Ajami NJ, O'Brien JL, Hutchinson DS, Smith DP, Wong MC, et al. Temporal development of the gut microbiome in early childhood from the TEDDY study. Nature. (2018) 562:583-8. doi: 10.1038/s41586-018-0617-x

137. Lemas DJ, Young BE, Baker PR, 2nd, Tomczik AC, Soderborg TK, Hernandez TL, et al. Alterations in human milk leptin and insulin are associated with early changes in the infant intestinal microbiome. Am J Clin Nutr. (2016) 103:1291-300. doi: 10.3945/ajcn.115.126375

138. Eggesbø M, Moen B, Peddada S, Baird D, Rugtveit J, Midtvedt $\mathrm{T}$, et al. Development of gut microbiota in infants not exposed to medical interventions. Apmis. (2011) 119:17-35. doi: 10.1111/j.1600-0463.2010.02688.x

139. Mehta R, Petrova A. Biologically active breast milk proteins in association with very preterm delivery and stage of lactation. J Perinatol. (2011) 31:5862. doi: 10.1038/jp.2010.68

140. Zhu L, Sha L, Li K, Wang Z, Wang T, Li Y, et al. Dietary flaxseed oil rich in omega-3 suppresses severity of type 2 diabetes mellitus via anti-inflammation and modulating gut microbiota in rats. Lipids Health Dis. (2020) 19:20. doi: 10.1186/s12944-019-1167-4

141. Vaarala O, Ilonen J, Ruohtula T, Pesola J, Virtanen SM, Härkönen T, et al. Removal of bovine insulin from cow's milk formula and early initiation of beta-cell autoimmunity in the FINDIA pilot study. Arch Pediatr Adolesc Med. (2012) 166:608-14. doi: 10.1001/archpediatrics.2011.1559

142. de Goffau MC, Luopajarvi K, Knip M, Ilonen J, Ruohtula T, Harkonen $\mathrm{T}$, et al. Fecal microbiota composition differs between children with beta-cell autoimmunity and those without. Diabetes. (2013) 62:1238-44. doi: $10.2337 / \mathrm{db} 12-0526$

143. Perazza LR, Daniel N, Dubois MJ, Pilon G, Varin TV, Blais M, et al. Distinct effects of milk-derived and fermented dairy protein on gut microbiota and cardiometabolic markers in diet-induced obese Mice. J Nutr. (2020) 150:2673-86. doi: 10.1093/jn/nxaa217

144. Qu L, Ren J, Huang L, Pang B, Liu X, Liu X, et al. Antidiabetic effects of Lactobacillus Casei fermented yogurt through reshaping gut microbiota structure in type 2 diabetic rats. J Agric Food Chem. (2018) 66:12696-705. doi: 10.1021 /acs.jafc.8b04874

145. Burton KJ, Kruger R, Scherz V, Munger LH, Picone G, Vionnet N, et al. Trimethylamine-N-oxide postprandial response in plasma and urine is lower after fermented compared to non-fermented dairy consumption in healthy adults. Nutrients. (2020) 12:234. doi: 10.3390/nu12010234

146. Fallani M, Amarri S, Uusijarvi A, Adam R, Khanna S, Aguilera $\mathrm{M}$, et al. Determinants of the human infant intestinal microbiota after the introduction of first complementary foods in infant samples from five European centres. Microbiology. (2011) 157(Pt 5):1385-92. doi: 10.1099/mic.0.042143-0

147. Iozzo P, Sanguinetti E. Early dietary patterns and microbiota development: still a way to go from descriptive interactions to health-relevant solutions. Front Nutr. (2018) 5:5. doi: 10.3389/fnut.2018.00005

148. Laursen MF, Bahl MI, Michaelsen KF, Licht TR. First foods and gut microbes. Front Microbiol. (2017) 8:356. doi: 10.3389/fmicb.2017.00356

149. Differding MK, Benjamin-Neelon SE, Hoyo C, Østbye T, Mueller NT. Timing of complementary feeding is associated with gut microbiota diversity and composition and short chain fatty acid concentrations over the first year of life. BMC Microbiol. (2020) 20:56. doi: 10.1186/s12866-020-01723-9

150. de la Cuesta-Zuluaga J, Mueller NT, Álvarez-Quintero R, VelásquezMejía EP, Sierra JA, Corrales-Agudelo V, et al. Higher fecal short-chain fatty acid levels are associated with gut microbiome dysbiosis, obesity, hypertension and cardiometabolic disease risk factors. Nutrients. (2018) 11:51. doi: $10.3390 /$ nu11010051
151. Sekirov I, Russell SL, Antunes LC, Finlay BB. Gut microbiota in health and disease. Physiol Rev. (2010) 90:859-904. doi: 10.1152/physrev.00045.2009

152. Turnbaugh PJ, Ridaura VK, Faith JJ, Rey FE, Knight R, Gordon JI. The effect of diet on the human gut microbiome: a metagenomic analysis in humanized gnotobiotic mice. Sci Transl Med. (2009) 1:6ra14. doi: $10.1126 /$ scitranslmed. 3000322

153. Walker AW, Sanderson JD, Churcher C, Parkes GC, Hudspith BN, Rayment $\mathrm{N}$, et al. High-throughput clone library analysis of the mucosa-associated microbiota reveals dysbiosis and differences between inflamed and noninflamed regions of the intestine in inflammatory bowel disease. $B M C$ Microbiol. (2011) 11:7. doi: 10.1186/1471-2180-11-7

154. Gorbach SL, Bengt E. Gustafsson memorial lecture. function of the normal human microflora. Scand J Infect Dis Suppl. (1986) 49:17-30.

155. Zimmer J, Lange B, Frick JS, Sauer H, Zimmermann K, Schwiertz A, et al. A vegan or vegetarian diet substantially alters the human colonic faecal microbiota. Eur J Clin Nutr. (2012) 66:53-60. doi: 10.1038/ejcn.2011.141

156. Singh RK, Chang H-W, Yan D, Lee KM, Ucmak D, Wong K, et al. Influence of diet on the gut microbiome and implications for human health. J Transl Med. (2017) 15:73. doi: 10.1186/s12967-017-1175-y

157. Kaur N, Bhadada SK, Minz RW, Dayal D, Kochhar R. Interplay between type 1 diabetes mellitus and celiac disease: implications in treatment. Digest Dis. (2018) 36:399-408. doi: 10.1159/000488670

158. Kaur P, Agarwala A, Makharia G, Bhatnagar S, Tandon N. Effect of glutenfree diet on metabolic control and anthropometric parameters in type 1 diabetes with subclinical celiac disease: a randomized controlled trial. Endocr Pract. (2020) 26:660-7. doi: 10.4158/EP-2019-0479

159. Creanza A, Lupoli R, Lembo E, Tecce N, Della Pepa G, Lombardi G, et al. Glycemic control and microvascular complications in adults with type 1 diabetes and long-lasting treated celiac disease: a case-control study. Diabetes Res Clin Pract. (2018) 143:282-7. doi: 10.1016/j.diabres.2018. 07.031

160. Pellegrini N, Agostoni C. Nutritional aspects of gluten-free products. J Sci Food Agric. (2015) 95:2380-5. doi: 10.1002/jsfa.7101

161. Fernández S, Molina IJ, Romero P, González R, Peña J, Sánchez F, et al. Characterization of gliadin-specific Th17 cells from the mucosa of celiac disease patients. Am J Gastroenterol. (2011) 106:528-38. doi: 10.1038/ajg.2010.465

162. Krishnareddy S. The microbiome in celiac disease. Gastroenterol Clin North Am. (2019) 48:115-26. doi: 10.1016/j.gtc.2018.09.008

163. Collado MC, Donat E, Ribes-Koninckx C, Calabuig M, Sanz Y. Specific duodenal and faecal bacterial groups associated with paediatric coeliac disease. J Clin Pathol. (2009) 62:264-9. doi: 10.1136/jcp.2008.061366

164. Sanz Y. Effects of a gluten-free diet on gut microbiota and immune function in healthy adult humans. Gut Microbes. (2010) 1:135-7. doi: $10.4161 /$ gmic.1.3.11868

165. Valitutti F, Cucchiara S, Fasano A. Celiac disease and the microbiome. Nutrients. (2019) 11:2403. doi: 10.3390/nu11102403

166. Yang Q, Liang Q, Balakrishnan B, Belobrajdic DP, Feng QJ, Zhang W. Role of dietary nutrients in the modulation of gut microbiota: a narrative review. Nutrients. (2020) 12:381. doi: 10.3390/nu12020381

167. Yamamoto EA, Jorgensen TN. Relationships between vitamin D, gut microbiome, and systemic autoimmunity. Front Immunol. (2019) 10:3141. doi: 10.3389/fimmu.2019.03141

168. Soltys K, Stuchlikova M, Hlavaty T, Gaalova B, Budis J, Gazdarica J, et al. Seasonal changes of circulating 25-hydroxyvitamin D correlate with the lower gut microbiome composition in inflammatory bowel disease patients. Sci Rep. (2020) 10:6024. doi: 10.1038/s41598-020-62811-4

169. Halling ML, Kjeldsen J, Knudsen T, Nielsen J, Hansen LK. Patients with inflammatory bowel disease have increased risk of autoimmune and inflammatory diseases. World J Gastroenterol. (2017) 23:6137-46. doi: 10.3748/wjg.v23.i33.6137

170. Iyer N, Grizotte-Lake M, Duncan K, Gordon SR, Palmer ACS, Calvin $\mathrm{C}$, et al. Epithelium intrinsic vitamin A signaling co-ordinates pathogen clearance in the gut via IL-18. PLoS Pathog. (2020) 16:e1008360. doi: 10.1371/journal.ppat.1008360

171. Huda MN, Ahmad SM, Kalanetra KM, Taft DH, Alam MJ, Khanam A, et al. Neonatal vitamin A supplementation and vitamin A status are associated with gut microbiome composition in bangladeshi infants in early 
infancy and at 2 years of age. J Nutr. (2019) 149:1075-88. doi: 10.1093/jn/n $\mathrm{xz} 034$

172. Wilson R, Willis J, Gearry RB, Hughes A, Lawley B, Skidmore P, et al. SunGold kiwifruit supplementation of individuals with prediabetes alters gut microbiota and improves vitamin C status, anthropometric and clinical markers. Nutrients. (2018) 10:895. doi: 10.3390/nu10070895

173. Xu J, Xu C, Chen X, Cai X, Yang S, Sheng Y, et al. Regulation of an antioxidant blend on intestinal redox status and major microbiota in early weaned piglets. Nutrition. (2014) 30:584-9. doi: 10.1016/j.nut.2013.10.018

174. Tang M, Frank DN, Sherlock L, Ir D, Robertson CE, Krebs NF. Effect of vitamin $\mathrm{E}$ with therapeutic iron supplementation on iron repletion and gut microbiome in us iron deficient infants and toddlers. J Pediatr Gastroenterol Nutr. (2016) 63:379-85. doi: 10.1097/MPG.0000000000001154

175. Kasaikina MV, Kravtsova MA, Lee BC, Seravalli J, Peterson DA, Walter J, et al. Dietary selenium affects host selenoproteome expression by influencing the gut microbiota. FASEB J. (2011) 25:2492-9. doi: 10.1096/fj.11-181990

176. Takahashi K, Suzuki N, Ogra Y. Effect of gut microflora on nutritional availability of selenium. Food Chem. (2020) 319:126537. doi: 10.1016/j.foodchem.2020.126537

177. Villagomez-Estrada S, Perez JF, Darwich L, Vidal A, van Kuijk S, Melo-Duran $D$, et al. Effects of copper and zinc sources and inclusion levels of copper on weanling pig performance and intestinal microbiota. J Anim Sci. (2020) 98:skaal17. doi: 10.1093/jas/skaal17

178. Giorgini M, Vitale M, Bozzetto L, Ciano O, Giacco A, Rivieccio A, et al. Micronutrient intake in a cohort of Italian adults with type 1 diabetes: adherence to dietary recommendations. J Diabetes Res. (2017) 2017:2682319. doi: $10.1155 / 2017 / 2682319$

179. Cazeau RM, Huang H, Bauer JA, Hoffman RP. Effect of vitamins C and E on endothelial function in type 1 diabetes mellitus. J Diabetes Res. (2016) 2016:3271293. doi: 10.1155/2016/3271293

180. Uusitalo U, Liu X, Yang J, Aronsson CA, Hummel S, Butterworth $\mathrm{M}$, et al. Association of early exposure of probiotics and islet autoimmunity in the TEDDY study. JAMA Pediatr. (2016) 170:20-8. doi: 10.1001/jamapediatrics.2015.2757
181. Savilahti E, Härkönen T, Savilahti EM, Kukkonen K, Kuitunen M, Knip M. Probiotic intervention in infancy is not associated with development of beta cell autoimmunity and type 1 diabetes. Diabetologia. (2018) 61:2668-70. doi: 10.1007/s00125-018-4738-4

182. Yoo JY, Kim SS. Probiotics and prebiotics: present status and future perspectives on metabolic disorders. Nutrients. (2016) 8:173. doi: $10.3390 /$ nu 8030173

183. Mishra SP, Wang S, Nagpal R, Miller B, Singh R, Taraphder S, et al. Probiotics and prebiotics for the amelioration of type 1 diabetes: present and future perspectives. Microorganisms. (2019) 7:67. doi: 10.3390/microorganisms7030067

184. Gudi R, Perez N, Johnson BM, Sofi MH, Brown R, Quan S, et al. Complex dietary polysaccharide modulates gut immune function and microbiota, and promotes protection from autoimmune diabetes. Immunology. (2019) 157:70-85. doi: 10.1111/imm.13048

185. Ho J, Reimer RA, Doulla M, Huang C. Effect of prebiotic intake on gut microbiota, intestinal permeability and glycemic control in children with type 1 diabetes: study protocol for a randomized controlled trial. Trials. (2016) 17:347. doi: 10.1186/s13063-016-1486-y

186. Mariño E, Richards JL, McLeod KH, Stanley D, Yap YA, Knight J, et al. Gut microbial metabolites limit the frequency of autoimmune $\mathrm{T}$ cells and protect against type 1 diabetes. Nat Immunol. (2017) 18:552-62. doi: 10.1038/ni.3713

Conflict of Interest: The authors declare that the research was conducted in the absence of any commercial or financial relationships that could be construed as a potential conflict of interest.

Copyright $\odot 2020$ Verduci, Mameli, Amatruda, Petitti, Vizzuso, El Assadi, Zuccotti, Alabduljabbar and Terranegra. This is an open-access article distributed under the terms of the Creative Commons Attribution License (CC BY). The use, distribution or reproduction in other forums is permitted, provided the original author(s) and the copyright owner(s) are credited and that the original publication in this journal is cited, in accordance with accepted academic practice. No use, distribution or reproduction is permitted which does not comply with these terms. 